Prepared in cooperation with Faulkner County

Geophysical Characterization of the Lollie Levee near Conway, Arkansas, using Capacitively Coupled Resistivity, Coring, and Direct Push Logging

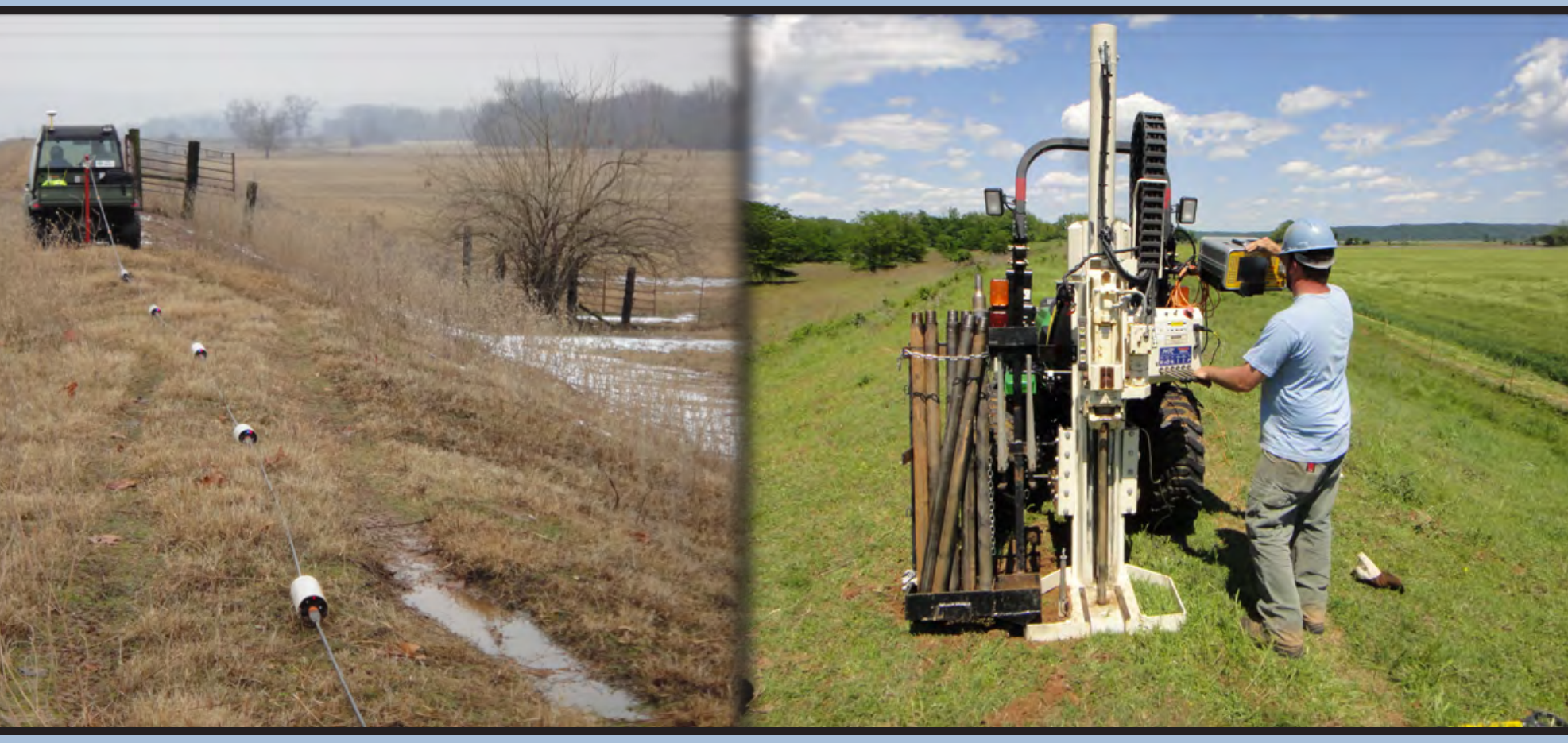

Data Series Report 640 


\section{Front cover:}

Left photograph, Collection of resistivity data along Lollie Levee, Faulkner County, Arkansas, February 7, 2011 (Photograph by Jonathan A. Gillip). Right photograph, Geoprobe direct push coring and direct push logging on Lollie Levee, Faulkner County, Arkansas, May 4, 2011 (Photograph by Jonathan A. Gillip). 


\section{Geophysical Characterization of the Lollie Levee near Conway, Arkansas, using Capacitively Coupled Resistivity, Coring, and Direct Push Logging}

By Jonathan A. Gillip and Jason D. Payne

Prepared in cooperation with Faulkner County

Data Series Report 640 


\section{U.S. Department of the Interior \\ KEN SALAZAR, Secretary \\ U.S. Geological Survey \\ Marcia K. McNutt, Director}

U.S. Geological Survey, Reston, Virginia: 2011

This and other USGS information products are available at http://store.usgs.gov/

U.S. Geological Survey

Box 25286, Denver Federal Center

Denver, CO 80225

To learn about the USGS and its information products visit http://www.usgs.gov/ 1-888-ASK-USGS

Any use of trade, product, or firm names is for descriptive purposes only and does not imply endorsement by the U.S. Government.

Although this report is in the public domain, permission must be secured from the individual copyright owners to reproduce any copyrighted materials contained within this report.

Suggested citation:

Gillip, J.A., and Payne, J.D., 2011, Geophysical characterization of the Lollie Levee near Conway, Arkansas, using capacitively coupled resistivity survey, coring, and direct push logging: U.S. Geological Survey Data Series Report 640, $27 \mathrm{p}$. 


\section{Contents}

Abstract
Introduction
Purpose and Scope
Geophysical Investigation Methods
Crew and Schedule of Survey Data Acquisition Activities
Results
Summary
References

\section{Figures}

1. Map showing the location of Lollie Levee, Faulkner County, Arkansas.............................2

2. Diagram showing capacitively coupled resistivity acquisition system setup

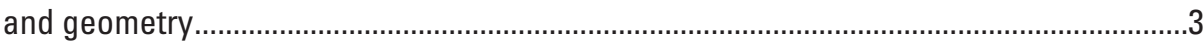

3. Photograph showing collection of resistivity data along Lollie Levee, Faulkner County, Arkansas, February 7, 2011...............................................................

4. Map showing the processed global positioning system path data and section location for resistivity survey data along the top of Lollie Levee, Faulkner County, Arkansas

5. Map showing the processed global positioning system path data and section location for resistivity survey data along the toe of Lollie Levee, Faulkner County, Arkansas.

6. Map showing the location of cores and direct push logs on Lollie Levee, Faulkner County, Arkansas.................................................................................................

7. Photograph showing geoprobe direct push coring and direct push logging on Lollie Levee, Faulkner County, Arkansas, May 4, $2011 .$.

8. Diagram showing core 1 direct push resistivity log and core description, taken from Lollie Levee, Faulkner County, Arkansas.....

9. Diagram showing core 2 direct push resistivity log and core description, taken from Lollie Levee, Faulkner County, Arkansas.

10. Diagram showing core 3 direct push resistivity log and core description, taken from Lollie Levee, Faulkner County, Arkansas .

11. Diagram showing core 4 direct push resistivity log and core description, taken from Lollie Levee, Faulkner County, Arkansas...

12. Diagram showing core 5 direct push resistivity log and core description, taken from Lollie Levee, Faulkner County, Arkansas..

13. Diagram showing core 6 direct push resistivity log and core description, taken from Lollie Levee, Faulkner County, Arkansas.

14. Diagram showing core 7 direct push resistivity log and core description, taken from Lollie Levee, Faulkner County, Arkansas..... 
15. Graph showing $A$. Resistivity survey along the top of Lollie Levee, Faulkner County, Arkansas, 0 to 4,000 feet. Core 1 is shown in figure 8 . B. Resistivity survey along the toe of Lollie Levee, Faulkner County, Arkansas, 0 to 4,000 feet

16. Graph showing $A$. Resistivity survey along the top of Lollie Levee, Faulkner County, Arkansas, 4,000 to 8,000 feet. Core 2 is shown in figure 9 . $B$. Resistivity survey along the toe of Lollie Levee, Faulkner County, Arkansas, 4,000 to 8,000 feet

17. Graph showing $A$. Resistivity survey along the top of Lollie Levee, Faulkner County, Arkansas, 8,000 to 12,000 feet. Core 3 is shown in figure 10. $B$. Resistivity survey along the toe of Lollie Levee, Faulkner County, Arkansas, 8,000 to 12,000 feet

18. Graph showing $A$. Resistivity survey along the top of Lollie Levee, Faulkner County, Arkansas, 12,000 to 16,000 feet. Core 4 is shown in figure 11. $B$. Resistivity survey along the toe of Lollie Levee, Faulkner County, Arkansas, 12,000 to 16,000 feet

19. Graph showing $A$. Resistivity survey along the top of Lollie Levee, Faulkner County, Arkansas, 16,000 to 20,000 feet. $B$. Resistivity survey along the toe of Lollie Levee, Faulkner County, Arkansas, 16,000 to 20,000 feet.

20. Graph showing $A$. Resistivity survey along the top of Lollie Levee, Faulkner County, Arkansas, 20,000 to 24,000 feet. Core 5 is shown in figure 12 . B. Resistivity survey along the toe of Lollie Levee, Faulkner County, Arkansas, 20,000 to 24,000 feet.

21. Graph showing $A$. Resistivity survey along the top of Lollie Levee, Faulkner County, Arkansas, 24,000 to 28,000 feet. Core 6 is shown in figure 13 . $B$. Resistivity survey along the toe of Lollie Levee, Faulkner County, Arkansas, 24,000 to 28,000 feet.

22. Graph showing $A$. Resistivity survey along the top of Lollie Levee, Faulkner County, Arkansas, 28,000 to 32,000 feet. $B$. Resistivity survey along the toe of Lollie Levee, Faulkner County, Arkansas, 28,000 to 32,000 feet.

23. Graph showing $A$. Resistivity survey along the top of Lollie Levee, Faulkner County, Arkansas, 32,000 to 36,000 feet. Core 7 is shown in figure 14 . $B$. Resistivity survey along the toe of Lollie Levee, Faulkner County, Arkansas, 32,000 to 36,000 feet. .26

\section{Tables}

1. Published resistivity values of geologic materials

\section{Conversion Factors}

Inch/Pound to SI

\begin{tabular}{|c|c|c|}
\hline Multiply & By & To obtain \\
\hline \multicolumn{3}{|c|}{ Length } \\
\hline inch (in.) & 2.54 & centimeter $(\mathrm{cm})$ \\
\hline foot (ft) & 0.3048 & meter $(\mathrm{m})$ \\
\hline mile (mi) & 1.609 & kilometer $(\mathrm{km})$ \\
\hline
\end{tabular}

Vertical coordinate information is referenced to the North American Vertical Datum of 1988 (NAVD 88).

Horizontal coordinate information is referenced to the North American Datum of 1983 (NAD 83).

Altitude, as used in this report, refers to distance above the vertical datum. 


\title{
Geophysical Characterization of the Lollie Levee near Conway, Arkansas, using Capacitively Coupled Resistivity, Coring, and Direct Push Logging
}

\author{
By Jonathan A. Gillip and Jason D. Payne
}

\begin{abstract}
A geophysical characterization of Lollie Levee near Conway, Arkansas, was conducted in February 2011. A capacitively coupled resistivity survey (using Geometric's OhmMapper) was completed along the top and toe of the 6.7-mile levee. Two-dimensional inversions were conducted on the geophysical data. As a quality-control measure, cores and direct push logs were taken at approximately 1-mile intervals along the levee.

The capacitively coupled resistivity survey, the coring, and the direct push logs were used to characterize the geologic materials. Comparison of the cores and the direct push log data, along with published resistivity values, indicates that resistivity values of $200 \mathrm{Ohm}$-meters or greater represent relatively clean sand, with decreasing resistivity values occurring with increasing silt and clay content. The cores indicated that the levee is composed of a heterogeneous mixture of sand, silt, and clay. The capacitively coupled resistivity sections confirm that the levee is composed of a heterogeneous mixture of high and low resistivity materials and show that the composition of the levee varies spatially. The geologic materials underlying the levee vary spatially as a result of the geologic processes that deposited them. In general, the naturally deposited geologic materials underlying the levee contain a greater amount of low resistivity materials in the southern extent of the levee.
\end{abstract}

\section{Introduction}

Many levees in Arkansas are constructed on complex assemblages of clay, sand, and gravel. Sand deposits are susceptible to preferential scour during high-water events. Additionally, locally sourced materials used for levee construction may contain materials that could weaken the levee. As such, it is important to know the distribution of geologic materials under levees to evaluate potential weaknesses. Complex subsurface geology can be characterized using surface-geophysical methods. Successful characterization of levee materials and subsurface geology has been accomplished using capacitively coupled resistivity data (Asch and others, 2008).

The Lollie Levee in Faulkner County (fig. 1) was built in the late 1920s to protect agricultural land. Prior to the 1990s, there were not many structures or valuable property protected by the levee. Since that time, Conway has expanded westward and the value of the property protected by the levee has increased dramatically. Although the levee has successfully contained the Arkansas River during past floods, the condition of the aging levee is not fully known. This report discusses a geophysical survey that was designed to characterize the geologic materials of the levee.

\section{Purpose and Scope}

The purpose of this geophysical investigation was to improve the understanding of geologic materials of the Lollie Levee and the underlying geologic materials. An integrated approach using a capacitively coupled resistivity survey, coring, and direct push logging was used in this investigation. The geophysical investigation included the collection of capacitively coupled resistivity survey data along the top and one toe of the levee and the collection of seven cores on approximately a 1-mile interval to confirm the results of the geophysical survey. At the time the cores were taken, the Geoprobe coring rig was equipped with a direct push logging tool that allowed the collection of resistivity logs as an additional quality-control component. This proved beneficial because the geologic materials within the levee were unconsolidated and experienced mixing and compaction during the coring. 


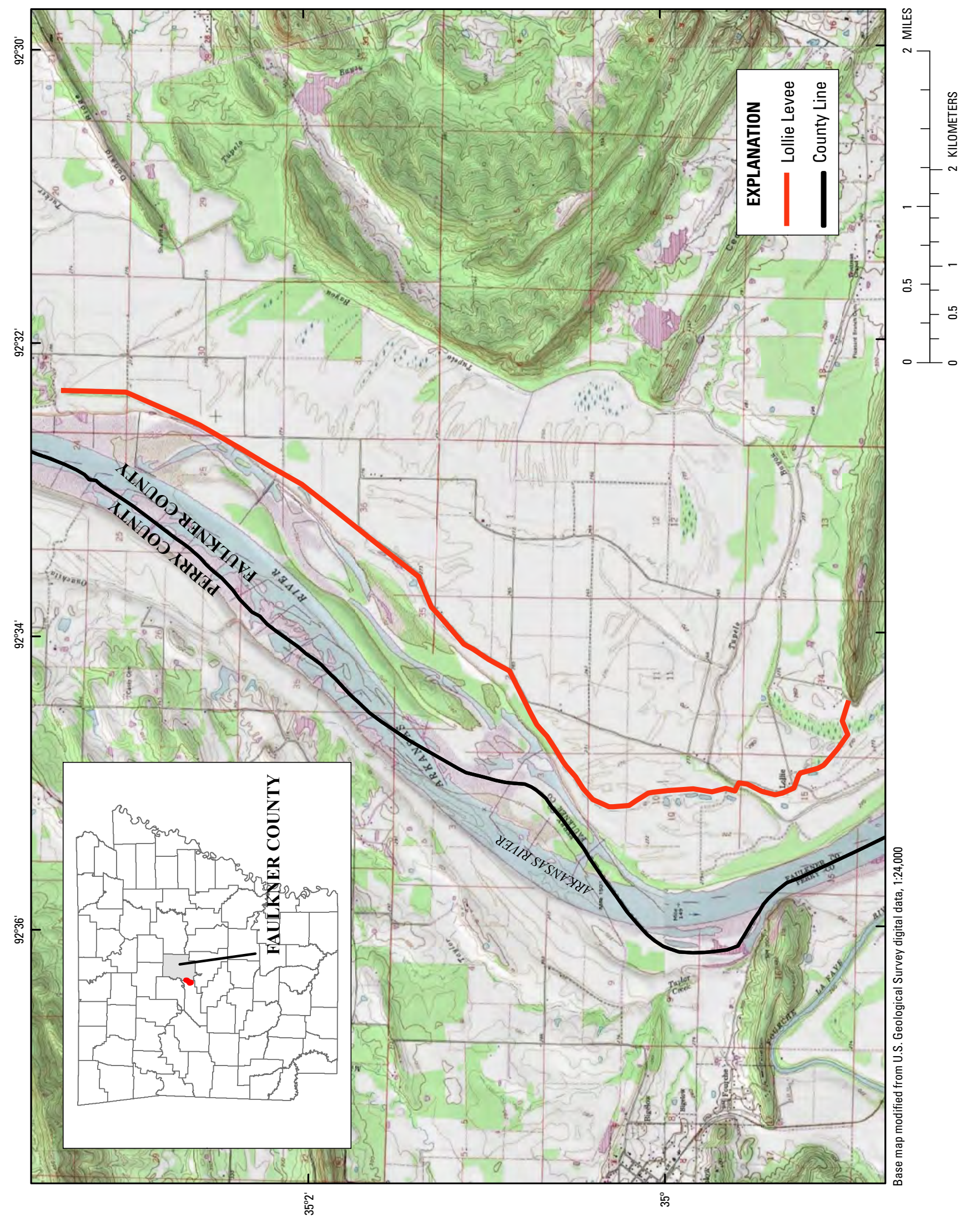

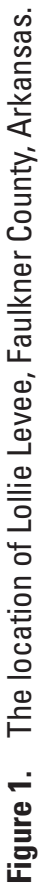




\section{Geophysical Investigation Methods}

\section{Crew and Schedule of Survey Data Acquisition Activities}

The U.S. Geological Survey (USGS) geophysical survey of the Lollie Levee was completed on February 7-8, 2011. The cores and direct push logs were taken on May 2-4, 2011.

\section{Capacitively Coupled Resistivity Survey}

This investigation used a capacitively coupled resistivity system (Geometric's OhmMapper) designed to measure subsurface resistivity in areas with high surface electrical resistivity (Geometrics, 2004). Investigation using traditional galvanically coupled resistivity systems was impractical because of the length of the levee, which was to be surveyed. In galvanically coupled resistivity systems, electrical current is transferred into the ground from metal electrodes in direct contact with the wet soils in the subsurface. In capacitively coupled resistivity systems, electrical current is produced in the ground because of a capacitively coupled alternating current source operating at about 16,500 hertz $(\mathrm{Hz})$. One of the primary advantages to using the capacitively coupled resistivity system is that the array is towed and miles of data can be collected in a relatively short amount of time.

The OhmMapper consists of an ungrounded (without electrodes placed into the ground) dipole transmitter and receiver. The operating principle is relatively simple: an alternating current (AC) is capacitively coupled into the ground at a particular operating frequency by a transmitting dipole. The measured AC voltage coupled to the receiver's dipole is proportional to the resistivity of the ground between the dipoles. The transmitter and receiver are deployed in an in-line, axial dipole-dipole configuration (fig. 2) and are separated by an integer number of dipole lengths (for example, two or four). In this investigation, the dipoles were 16.4 feet in length. As with a direct current (DC) resistivity survey, an apparent resistivity is calculated by multiplying the appropriate geometric factor by the OhmMapper's received voltage, normalized by the transmitter current (Asch and others, 2008). The OhmMapper was pulled along the ground as a streamer by an all-terrain vehicle to collect nearly continuous apparent resistivity data (fig. 3). The depth of investigation for the resistivity survey averaged about 33 feet (approximately 10 meters).

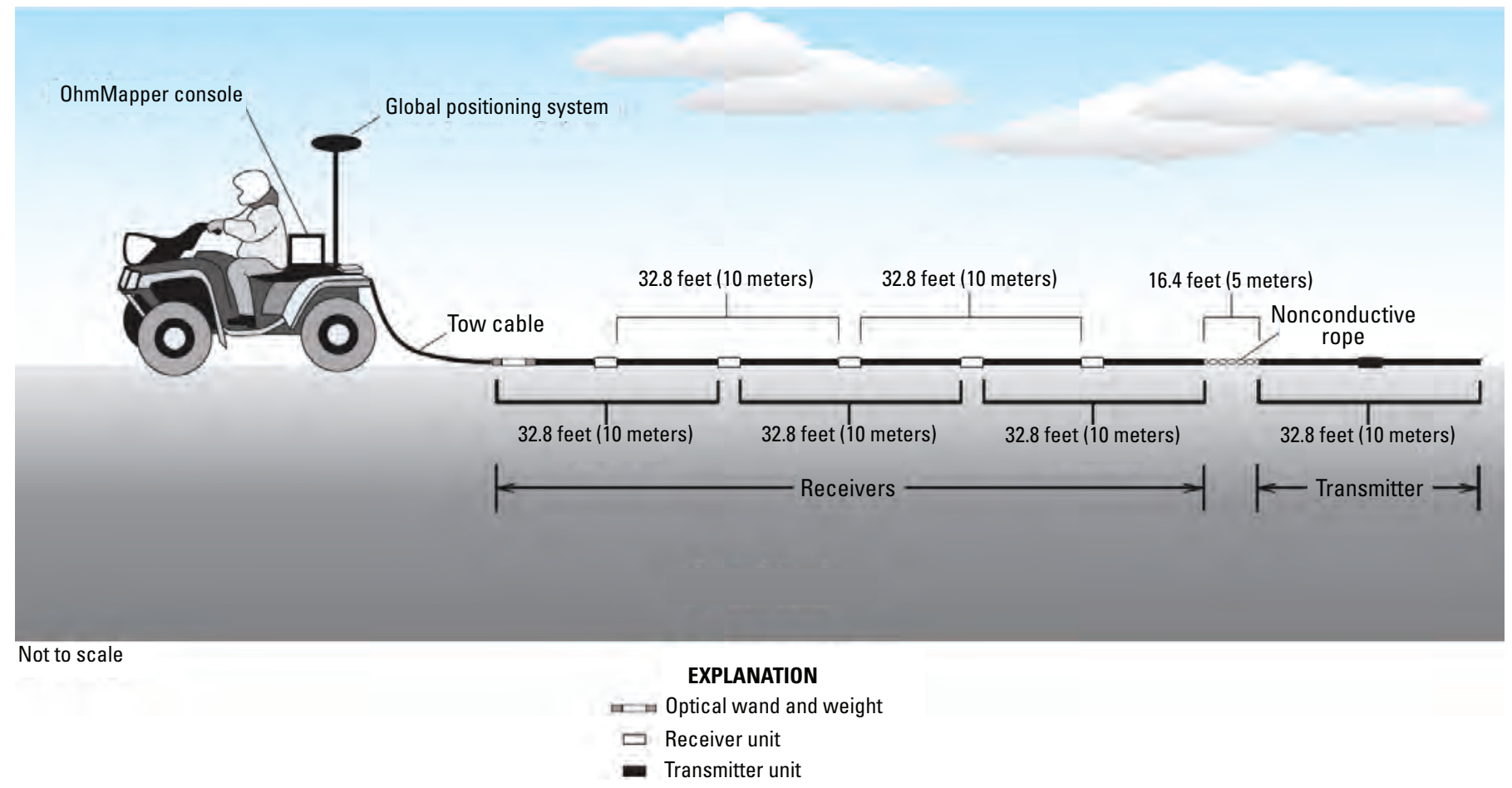

Figure 2. Capacitively coupled resistivity acquisition system setup and geometry (modified from Ball and others, 2006). 


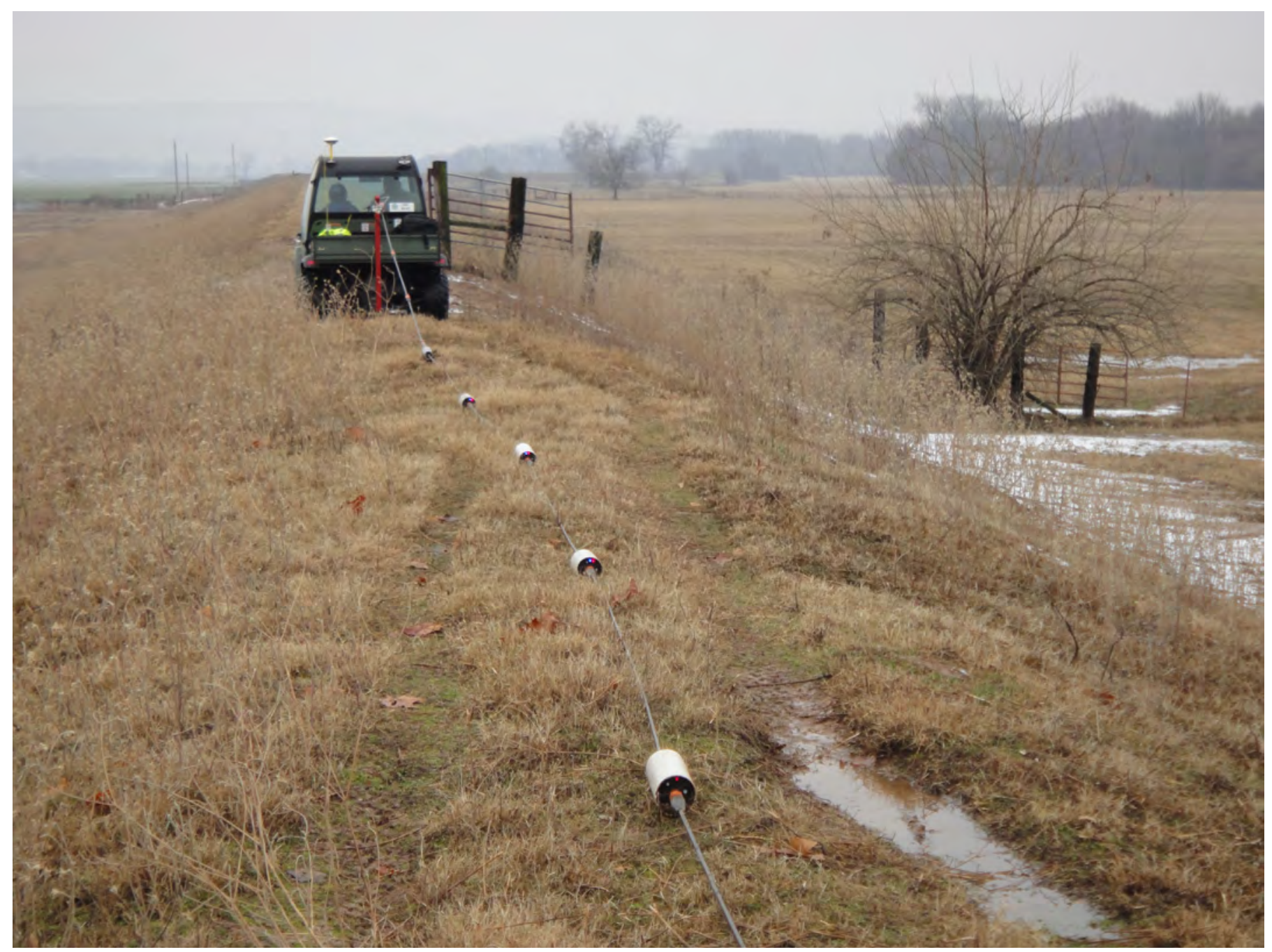

Figure 3. Collection of resistivity data along Lollie Levee, Faulkner County, Arkansas, February 7, 2011.

These data were collected in 33 traverses, which represent segments of resistivity data. Traverses 1-16 were collected along one toe of the levee and traverses 17-33 were collected along the top of the levee. These traverses were compiled into a continuous section for both the top and toe of the levee (location is shown on figs. 4-5; data are presented in figs. 15-23). Small data gaps occur in the sections where the capacitively coupled resistivity survey equipment had to be moved around fences or other obstacles. For the top of the levee, the capacitively coupled resistivity survey equipment was pulled near the center of the levee top. A notable data gap occurred from approximately 3,400 feet to 3,950 feet along the top of the levee because of an enclosed area with no access (fig. 4). For the toe of the levee, the capacitively coupled resistivity survey equipment was pulled on the side of the levee that allowed the best access. This resulted in the data along the toe of the levee being collected on parts of both sides of the levee. Because the levee is narrow, data from either side of the levee accurately represent the subsurface geology. From approximately 9,000 to 10,500 feet, the data for the toe of the levee was collected up to 200 feet from the levee because of extremely saturated conditions at the toe of the levee. Because of a large number of fences and other obstructions along the toe of the levee, other data gaps occur.

To accurately locate the geophysical data, a global positioning system (GPS), affixed to the all- terrain vehicle, collected positioning data as the resistivity data were collected. The data files were preprocessed using USGS programs 


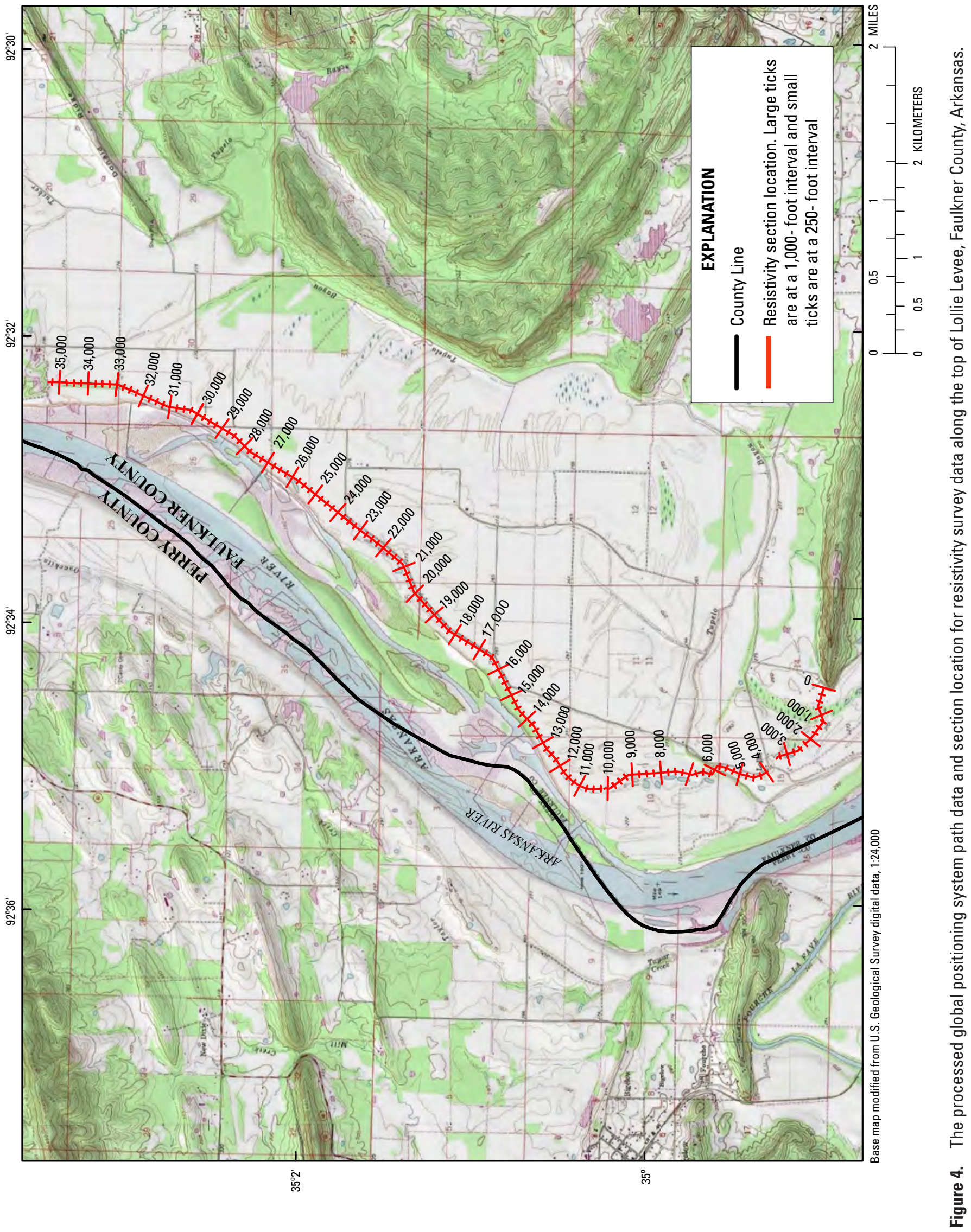




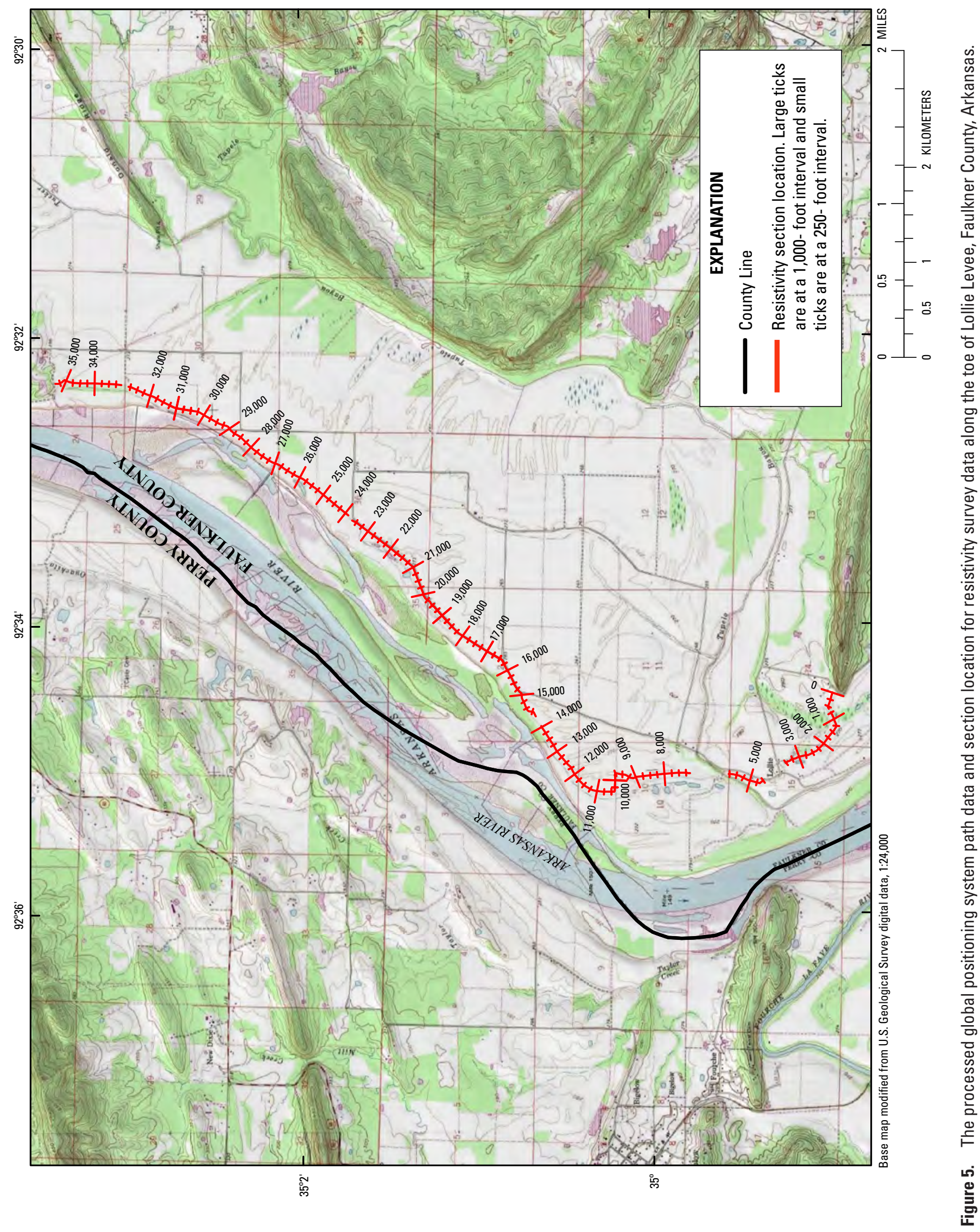


GPS-PathTool and OhmBin that are specifically designed to process resistivity survey data. The GPS-PathTool program allows editing of GPS data points recorded in the OhmMapper data files and interpolation through missing or bad data locations. Output from the GPS-PathTool program is input to the OhmBin program that performs data editing, binning, and averaging (Asch and others, 2008). The resulting GPS data for the top of the levee and the toe of the levee are shown in figures 4 and 5, respectively. Output from the OhmBin program is then input to the Advanced Geosciences, Inc., EarthImager 2D inversion program (Advanced Geosciences, Inc., 2007).

The main factors that affect the resistivity of a material are the grain size and the amount of mineralogical clay present. In the unsaturated zone, if no mineralogical clay is present, a fine-grained material will generally retain more water in the interconnected pore spaces than a coarse-grained material because of capillary forces. The fine-grained material (silts) will therefore have a lower resistivity compared to coarser grained materials (sands). Mineralogical clay conducts electricity both through the pore fluids (electrolytically) as well as through cation exchange (electronically). Therefore, the presence of even a small amount of mineralogical clay can dramatically decrease the overall bulk resistivity of a material. Because of the relation between grain size and resistivity, the resistivity method can be a useful tool in differentiating geologic materials that could affect the performance of the levee. Reynolds (1997), Sharma (1997), and Butler (2005) provide more detailed descriptions of the resistivity method and actual resistivity values for common geologic materials. The apparent resistivity values obtained using surface resistivity methods approximate actual values. Relative differences in the values are also indicative of different lithologies. Literature values of geologic materials encountered in the levee are shown below (table 1).

The data from the capacitively coupled resistivity survey are processed to provide a two-dimensional representation of the actual resistivity of the geologic materials. Apparent resistivity, as calculated from the field measurements, is the electrical resistivity over an equivalent electrically homogeneous and isotropic subsurface, and is used to represent the average resistivity of a more realistic, heterogeneous subsurface (Loke, 2000). To help determine the "true" distribution of electrical resistivity in the subsurface, an inversion program develops a two-dimensional model consisting of rectangular blocks of individual resistivity values. The inversion program then determines the calculated system response (apparent resistivity) over that model, based on the field data-collection parameters including the type of array utilized, the distance between electrodes, and the number of measurements taken. The root mean square (RMS) difference between the measured and calculated apparent resistivities is used to determine the accuracy of the model. The inversion program then attempts to reduce the RMS difference by altering the model resistivity values and recalculating the apparent resistivity; this alteration is known as an "iteration." When the RMS difference between the calculated and measured apparent resistivity no longer improves more than 1 percent between iterations, a solution is reached. This final model represents a non-unique estimate of the "true" two-dimensional distribution of electrical resistivity within the subsurface. This inversion process is described in detail by Loke (2004). The inversion process resulted in a RMS difference of less than 3 percent on all sections of resistivity data. The final inverted OhmMapper data sections are displayed in figures 15 through 23 .

\section{Coring and Direct Push Logging}

Seven 2-inch diameter cores were taken from the levee (fig. 6) using a Geoprobe direct push coring system. The system uses a hydraulic hammer mounted on the back of a tractor (fig. 7) to drive a sampler with a 2-inch internal diameter into the ground. The sampler is lined with a plastic tube, which is removed with the core. The core is typically taken in 4-foot sections. The depth of cores ranged from 16 feet to 24 feet and all penetrated the levee. The cores were recovered in plastic sleeves and later described in a laboratory setting (figs. 8-14).

Table 1. Published resistivity values of geologic materials (from Reynolds, 1997).

[Ohm-m, Ohm-meter]

\begin{tabular}{lc}
\hline \multicolumn{1}{c}{ Geologic material } & Nominal resistivity (Ohm-m) \\
\hline Soil with 40 percent clay & 8 \\
Soil with 20 percent clay & 33 \\
Sandy clay/clayey sand & $30-215$ \\
Dry sandy soil & $80-1,050$ \\
Dry gravel & 1,400 \\
\hline
\end{tabular}




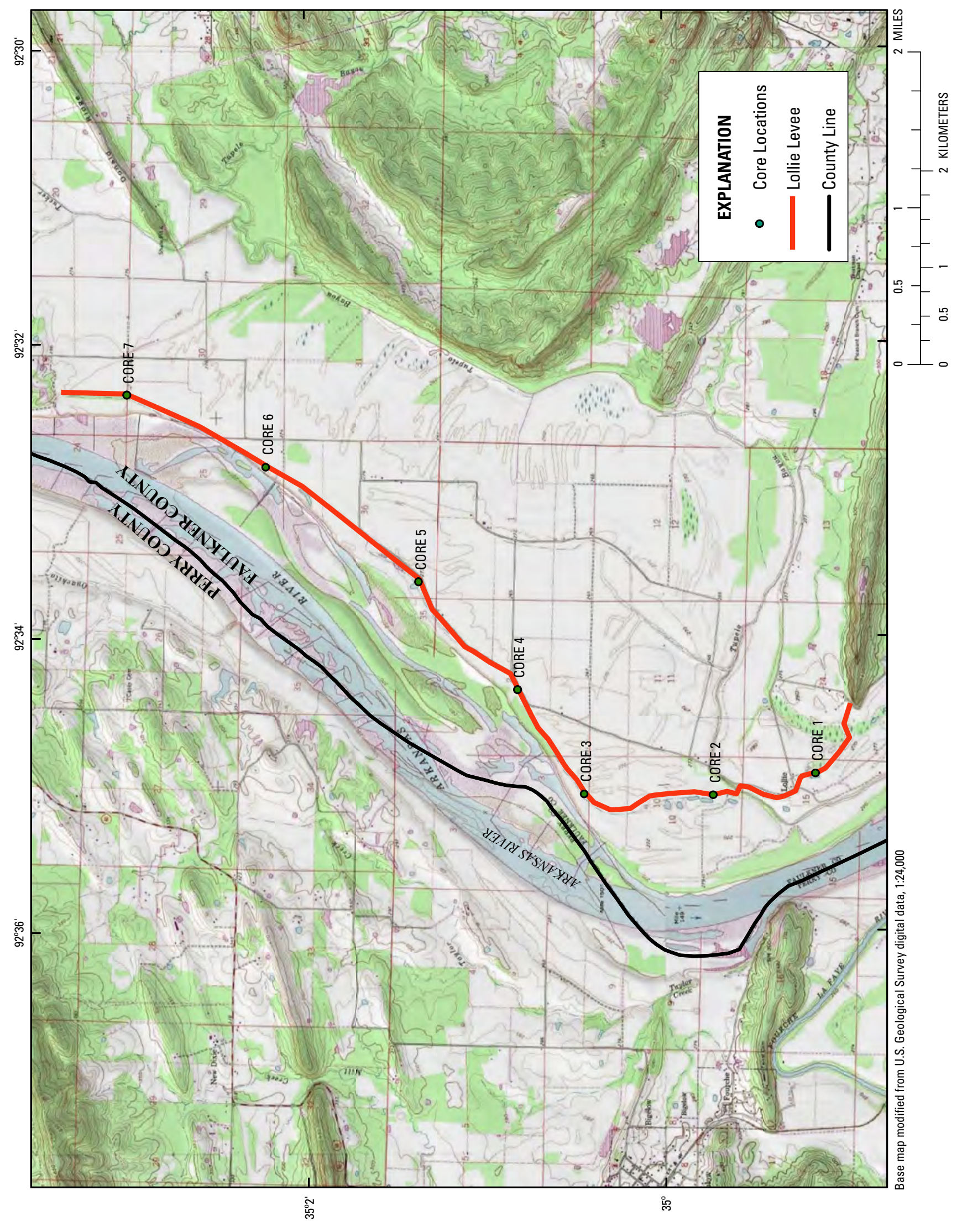

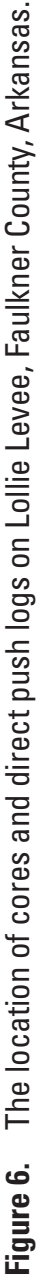




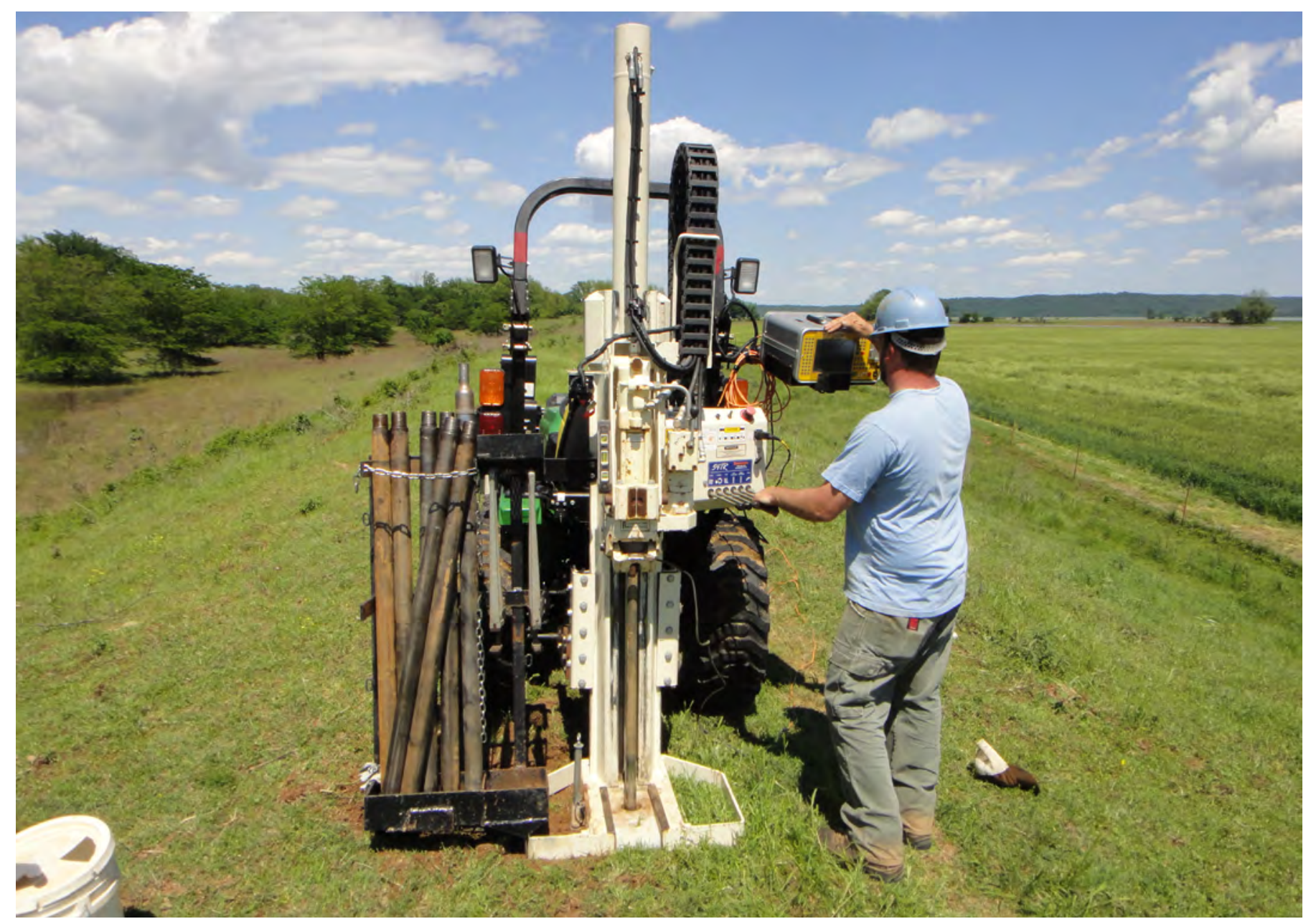

Figure 7. Geoprobe direct push coring and direct push logging on Lollie Levee, Faulkner County, Arkansas, May 4, 2011.

At the time the core was taken, a direct push log was taken in the immediate vicinity of the core using the Geoprobe Direct Image Electrical Conductivity System. The advantage of this system is that it measures the conductivity of the soil in place, with no compression or collapse. The direct push $\log$ recorded a measurement of electrical conductivity. The electrical conductivity was then converted to resistivity to allow comparison with the capacitively coupled resistivity data. Finer grained sediments, such as silts and clay, conduct electricity better (less resistive) than coarser sediments, such as sand and gravel (more resistive). Combined with a few cores at nearby sites, the direct push log can accurately characterize the geologic materials (Schulmeister and others, 2003; Geoprobe, 2011). Holes created in the process of collecting cores and direct push logs were immediately backfilled with expansive bentonite clay pellets.

Lollie Levee was constructed from locally derived geologic materials. During the construction, layers of materials were laid down and then compacted. The result of this process is a heterogeneous mixture of sand, silt, and clay. The cores taken from the levee were useful in identifying the general geologic materials present in the levee. With the geologic materials identified, the direct push logs provide an in place representation of the resistivity of the levee materials. The core descriptions and direct push logs are presented in figures 8 through 14 . 
Depth $\quad \begin{array}{ccc}\text { Direct Push Resistivity (Ohm-m) } & \text { Description of Core Materials }\end{array}$

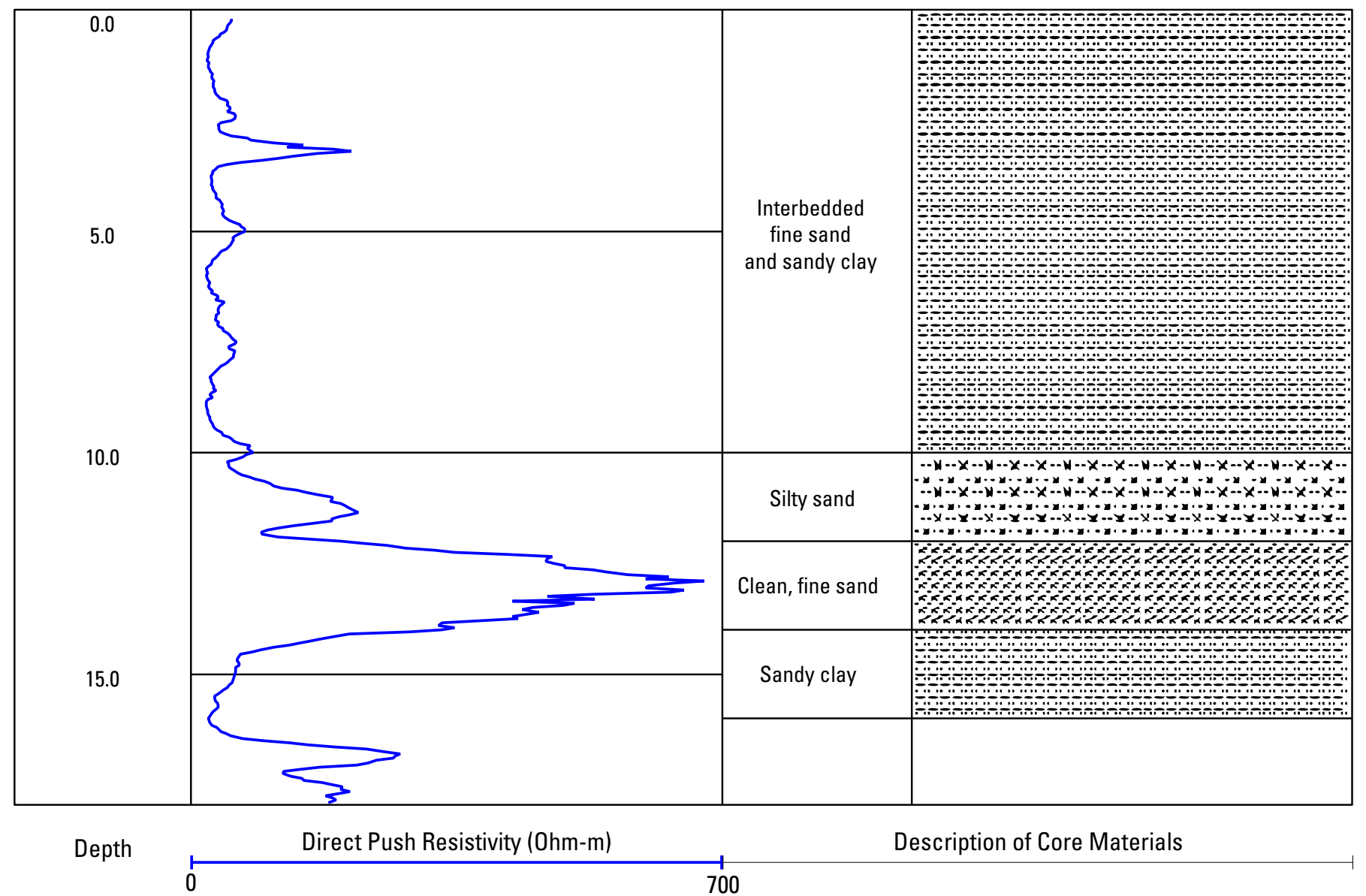

Figure 8. Core 1 direct push resistivity log and core description, taken from Lollie Levee, Faulkner County, Arkansas. Core is located at $34^{\circ} 59^{\prime} 09.3^{\prime \prime} \mathrm{N}, 92^{\circ} 34^{\prime} 55.8^{\prime \prime} \mathrm{W}$. Core depth is 16 feet. Direct push log depth is 17.9 feet. 


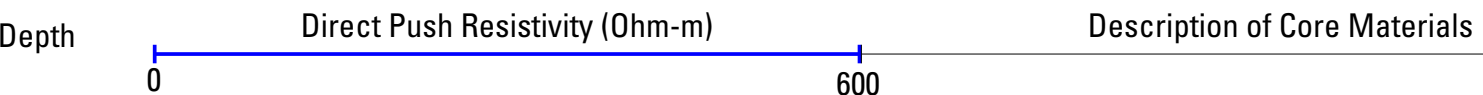

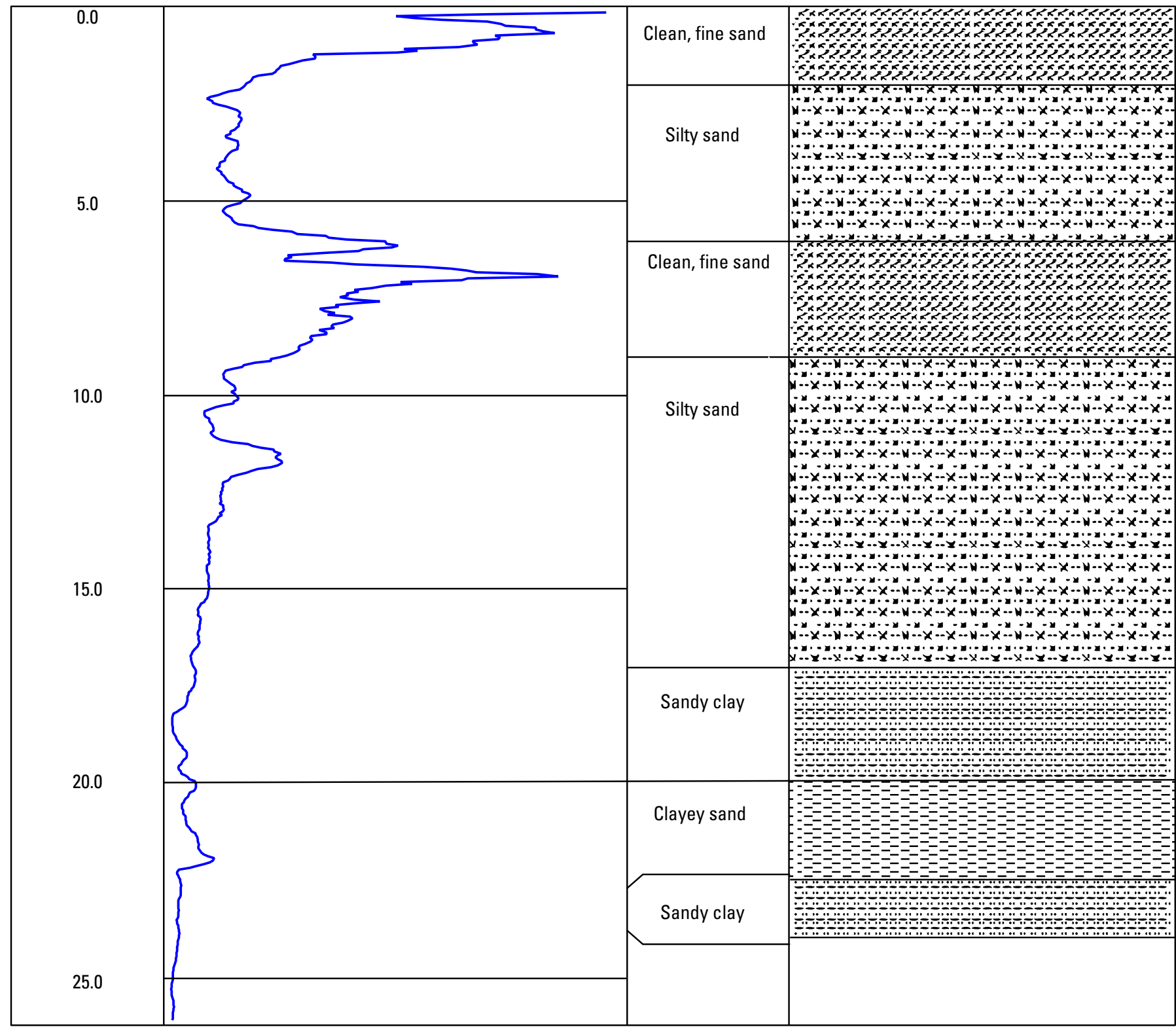

Depth

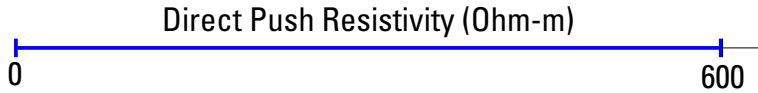

Description of Core Materials

Figure 9. Core 2 direct push resistivity log and core description, taken from Lollie Levee, Faulkner County, Arkansas. Core is located at $34^{\circ} 59^{\prime} 43.7^{\prime \prime} \mathrm{N}, 92^{\circ} 35^{\prime} 04.6^{\prime \prime} \mathrm{W}$. Core depth is 24 feet. Direct push log depth is 26.3 feet. 


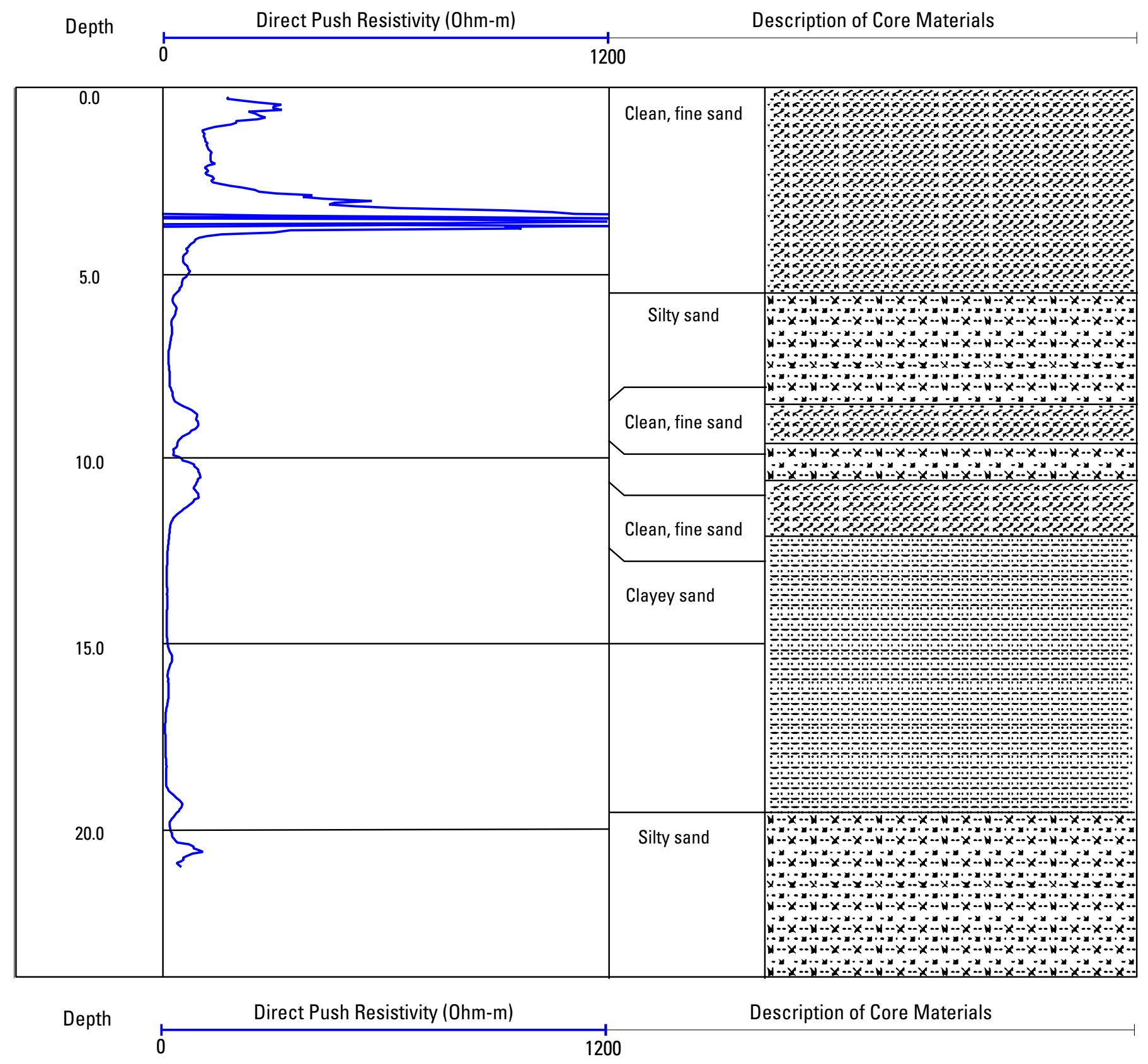

Figure 10. Core 3 direct push resistivity log and core description, taken from Lollie Levee, Faulkner County, Arkansas. Core is located at $35^{\circ} 00^{\prime} 27.0^{\prime \prime} \mathrm{N}, 92^{\circ} 35^{\prime} 04.0^{\prime \prime} \mathrm{W}$. Core depth is 24 feet. Direct push log depth is 21 feet. 


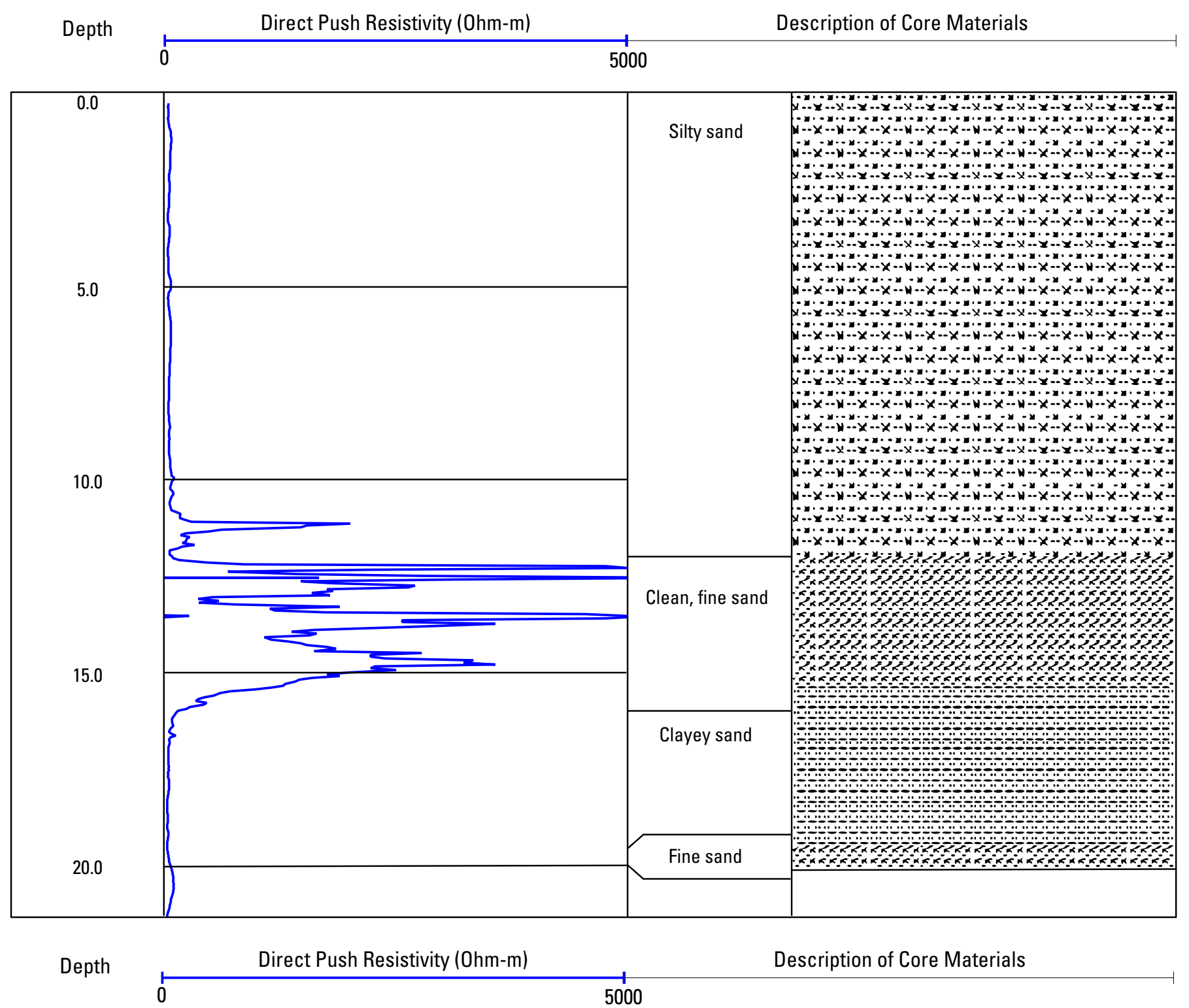

Figure 11. Core 4 direct push resistivity log and core description, taken from Lollie Levee, Faulkner County, Arkansas. Core is located at $35^{\circ} 00^{\prime} 49.2^{\prime \prime} \mathrm{N}, 92^{\circ} 34^{\prime} 21.5^{\prime \prime} \mathrm{W}$. Core depth is 20 feet. Direct push log depth is 21.35 feet. 

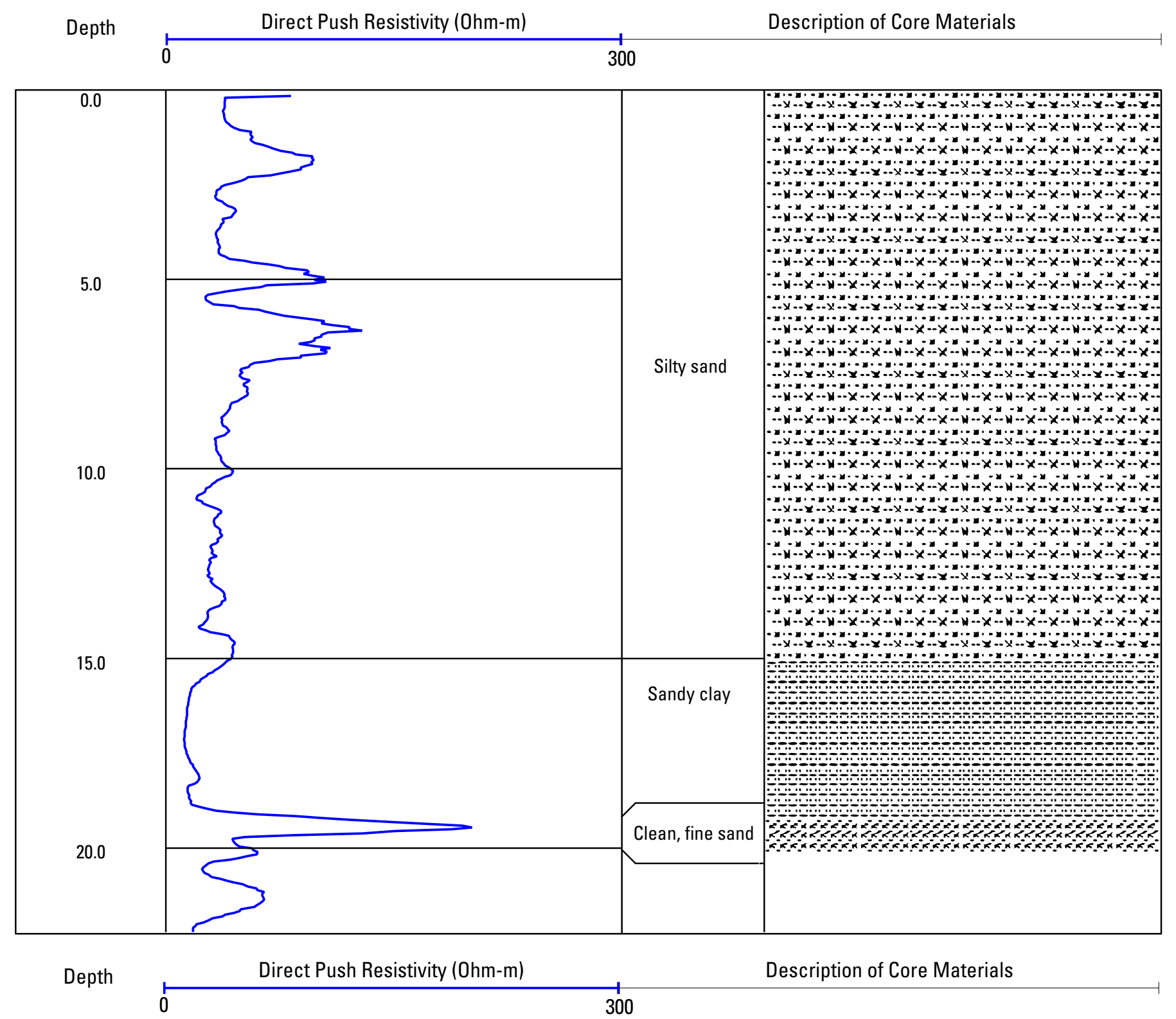

Figure 12. Core 5 direct push resistivity log and core description, taken from Lollie Levee, Faulkner County, Arkansas. Core is located at $35^{\circ} 01^{\prime} 22.2^{\prime \prime} \mathrm{N}, 92^{\circ} 33^{\prime} 37.3^{\prime \prime} \mathrm{W}$. Core depth is 20 feet. Direct push log depth is 22.2 feet. 
Depth

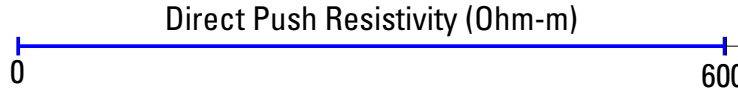

Description of Core Materials

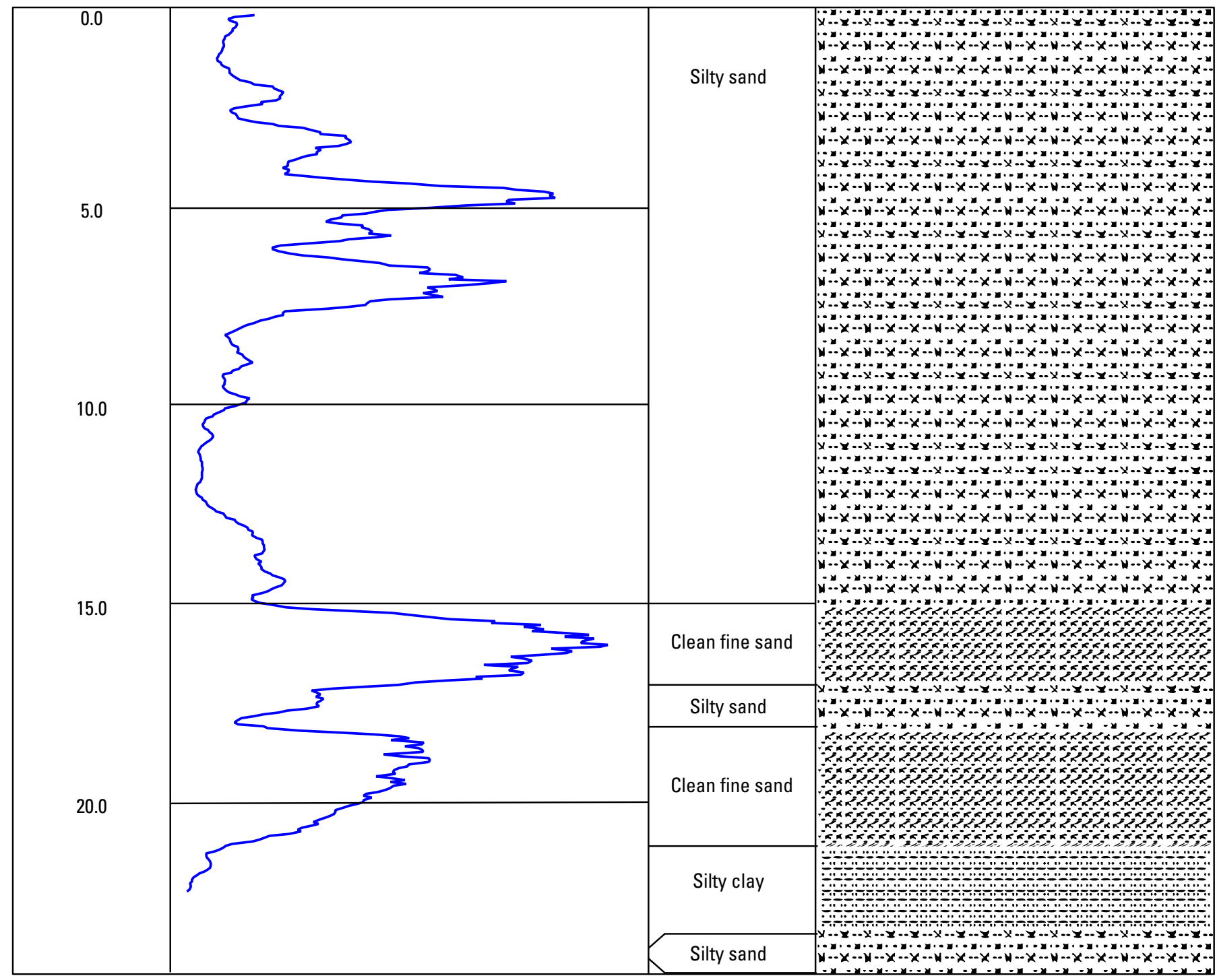

Depth

Direct Push Resistivity (Ohm-m)

Description of Core Materials

600

Figure 13. Core 6 direct push resistivity log and core description, taken from Lollie Levee, Faulkner County, Arkansas. Core is located at $35^{\circ} 02^{\prime} 13.4^{\prime \prime} \mathrm{N}, 92^{\circ} 32^{\prime} 50.1^{\prime \prime} \mathrm{W}$. Core depth is 24 feet. Direct push log depth is 22.2 feet. 
Depth
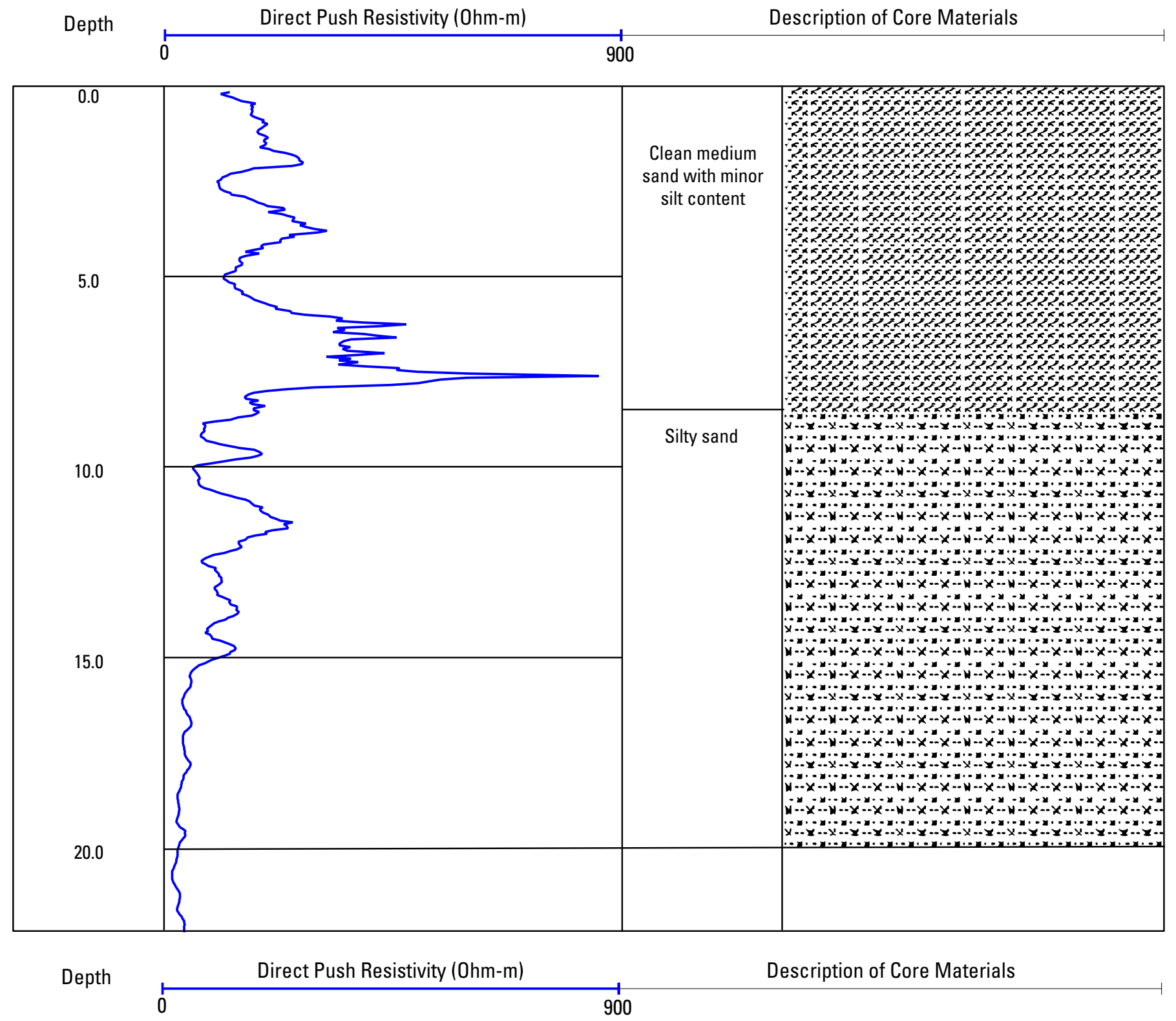

Figure 14. Core 7 direct push resistivity log and core description, taken from Lollie Levee, Faulkner County, Arkansas. Core is located at $35^{\circ} 03^{\prime} 00.0^{\prime \prime} \mathrm{N}, 92^{\circ} 32^{\prime} 20.6^{\prime \prime} \mathrm{W}$. Core depth is 20 feet. Direct push log depth is 22.2 feet. 


\section{Results}

The geophysical investigation yielded data indicating the levee is composed of a heterogeneous mixture of sand, silt, and clay. The geophysical data (figs. 4-5, figs. 15-23) are consistent with field observations of surface materials, data from the cores, and data from the direct push logs

(fig. 6, figs. 8-14).

Seven cores were taken from the levee at approximately 1-mile intervals (fig. 6). The cores were numbered 1-7, with Core 1 being the southernmost core and Core 7 being the northernmost core. Examinations of the cores in the laboratory indicate that the geologic materials composing the levee range from nearly pure sand to clay. While there are areas of relatively pure sand within the levee, much of the levee is sand with varying silt and clay content. Following is a summary of the physical core description and the resistivity values from the direct push logs. Core 1 contains sandy materials with varying silt and clay content with resistivity values ranging from around 30 to $700 \mathrm{Ohm}-\mathrm{m}$. From 12 to 14 feet, the core penetrated a clean, fine sand with a resistivity of up to about 700 Ohm-m (fig. 8). Core 2 contained sandy materials near the surface with resistivities up to about $580 \mathrm{Ohm}-\mathrm{m}$. The core penetrated into sandy materials with a substantial silt and clay content at a 10 -foot depth, which had resistivities ranging from about 10 to $140 \mathrm{Ohm}-\mathrm{m}$ (fig. 9). Core 3 penetrates sandy materials to 6 feet with resistivities of approximately 200 to $1,600 \mathrm{Ohm}-\mathrm{m}$. A spike in the resistivity curve (10,000 Ohm$\mathrm{m}$ ) occurs at 4.5 feet, which is consistent with the direct push logging tool encountering a void. From 6 to 21 feet, the core penetrates materials with varying silt and clay content with resistivity values ranging from about 30 to $100 \mathrm{Ohm}-\mathrm{m}$ (fig. 10). Core 4 penetrated silty sand to approximately 12 feet with resistivity values ranging from about 50 to $100 \mathrm{Ohm}-\mathrm{m}$ and then encountered a 4-foot interval of clean, fine sand with anomalously high resistivity values (up to approximately 7,000 Ohm-m). These high resistivity values are likely caused by poor contact with the logging tool because the materials were very dry. The core confirms that this interval is dry, clean, fine sand. The core then passes into clayey materials with a resistivity from around 30 to $150 \mathrm{Ohm}-\mathrm{m}$ (fig. 11). Core 5 contains sandy material with varying silt and clay content with resistivity values ranging from approximately 10 to $120 \mathrm{Ohm}-\mathrm{m}$. There is a thin interval of relatively clean sand at about 19 to 20 feet that had a resistivity of approximately 200 Ohm-m (fig. 12). Core 6 penetrates sandy material with a minor silt content to 15 feet, with resistivity values ranging from approximately 40 to $500 \mathrm{Ohm}-\mathrm{m}$. The core then penetrates a 6-foot interval of mostly clean sand that has resistivities of up to $550 \mathrm{Ohm}-\mathrm{m}$ before penetrating into sandy clay with a resistivity of approximately 120 Ohm-m (fig. 13). Core 7 penetrates clean, medium sand to a depth of 8.5 feet with resistivities of approximately 110 to $860 \mathrm{Ohm}-\mathrm{m}$. The core then penetrates silty sand with resistivities ranging from approximately 20 to $250 \mathrm{Ohm}-\mathrm{m}$ (fig. 14). Comparison of the cores and the direct push log data (figs. 8-14), along with published resistivity values (table 1 ), indicates that resistivity values of approximately $200 \mathrm{Ohm}-\mathrm{m}$ or greater represent relatively clean sand. The resistivity value decreases with increasing silt and clay content.

Figures 4 and 5 show the location of the resistivity sections along the top and toe of the levee, respectively. The section location is labeled from 0 to 35,400 feet along the path of the section starting at the southern end of the levee. On the sections, warmer colors (red) represent more resistive geologic materials and cooler colors (blue) represent less resistive geologic materials (figs. 15-23). Following is a summary of the resistivity data collected along the top and toe of Lollie Levee. For the purposes of this summary, high resistivity refers to resistivity greater than $200 \mathrm{Ohm}-\mathrm{m}$ and low resistivity refers to resistivity less than $200 \mathrm{Ohm}-\mathrm{m}$. From 0 to about 600 feet, the levee contains high resistivity materials. The underlying materials are low resistivity materials. From about 600 to 2,000 feet, the levee and underlying geologic materials contain a mixture of low and high resistivity materials. From about 2,000 to 3,000 feet, both the levee and the underlying geologic materials are mostly high resistivity materials. From about 3,000 to 3,400 feet, both the levee and the underlying geologic materials are a mixture of high and low resistivity materials (fig. 15). From about 4,000 to 5,900 feet, the levee and underlying geologic materials are mostly low resistivity, although a few small areas with higher resistivity occur. From about 5,900 feet to 9,375 feet, the levee contains high resistivity materials near the surface with some low resistivity materials mixed in. The underlying geologic materials are mostly low resistivity although the underlying materials have higher resistivity from about 8,500 to 9,375 feet. (figs. 16-17). From about 9,375 feet to 13,500 feet, both the levee materials and underlying geologic materials are high resistivity (figs. 17-18). From about 13,500 to 16,300 feet, both the levee materials and the underlying geologic materials are a mixture of low resistivity and high resistivity materials (figs. 18-19). From about 16,300 to 17,200 feet, the levee and the underlying geologic materials are composed mainly of low resistivity materials (fig. 19). From about 17,200 to 23,000 feet, both the levee materials and the underlying geologic materials are a mixture of low resistivity and high resistivity materials (figs. 19-20). From about 23,000 to 23,875 feet, both the levee and the underlying geologic materials are composed mostly of high resistivity materials (fig 20). From about 23,875 to 26,300 feet, both the levee materials and the underlying geologic materials are a mixture of low resistivity and high resistivity materials (figs. 20-21). From about 26,300 to 29,000 feet, the levee is composed mainly of high resistivity materials and the underlying geologic materials are composed of a mixture of low and high resistivity materials (figs. 21-22). The remainder of the levee (from about 29,000 to 35,400 feet) is composed of mostly high resistivity materials underlain by geologic materials composed of a mixture of high and low resistivity materials (figs. 22-23). The resistivity sections indicate that the levee is composed of a heterogeneous mixture of high and low resistivity materials. The resistivity of the geologic materials underlying the levee varies spatially as a result of the geologic processes that deposited them. In general, the naturally deposited geologic materials underlying the levee are less resistive in the southern extent of the levee. 

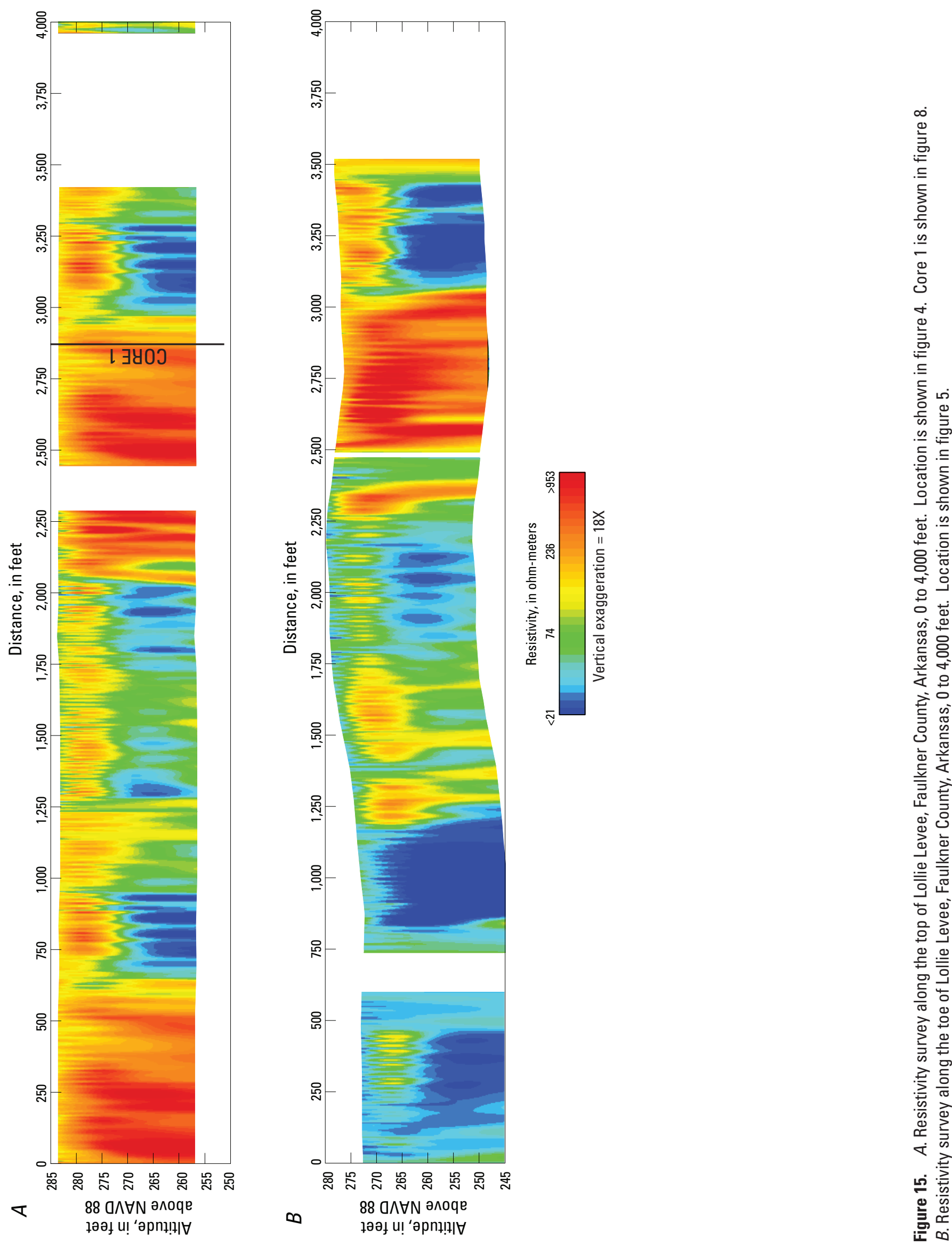

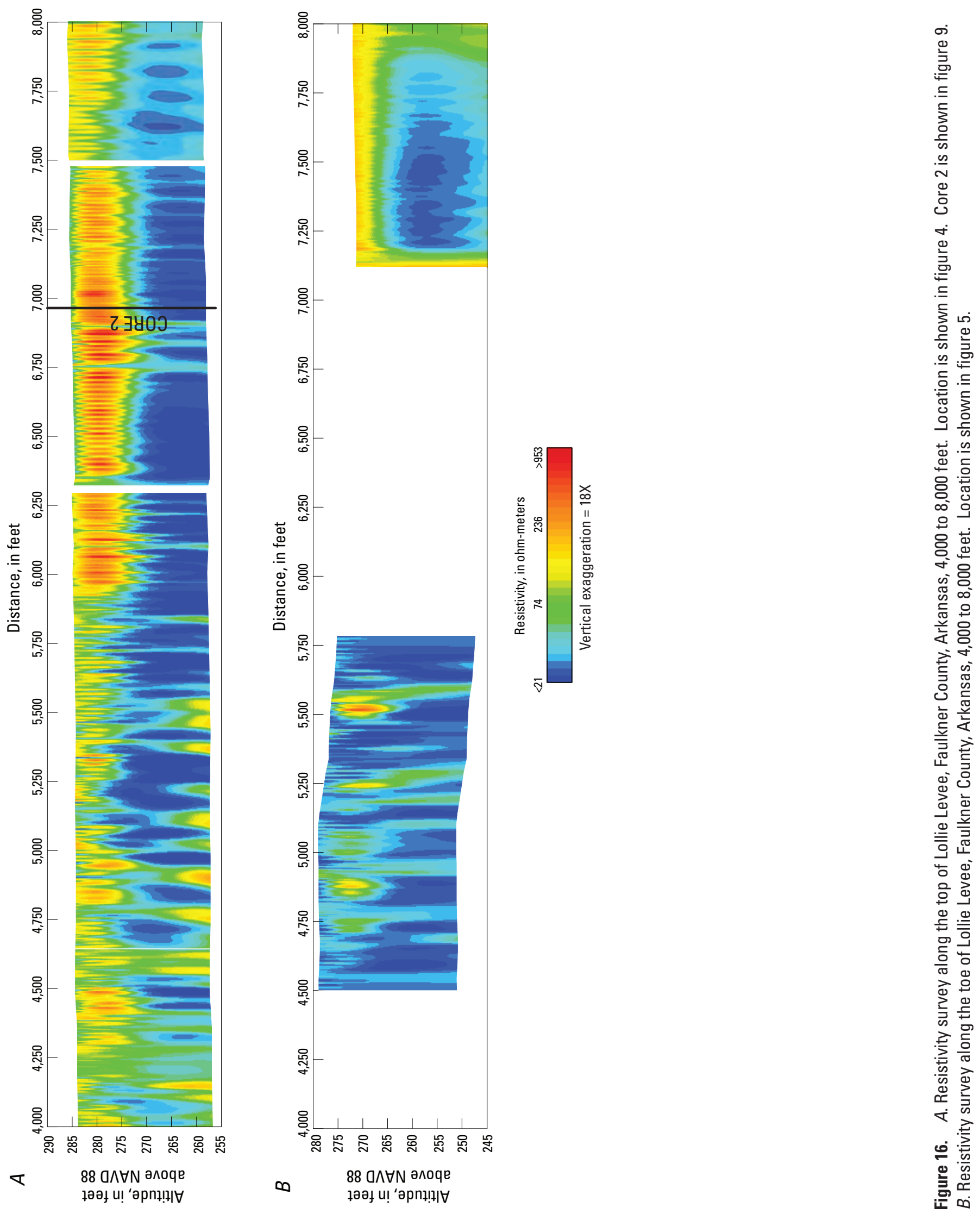

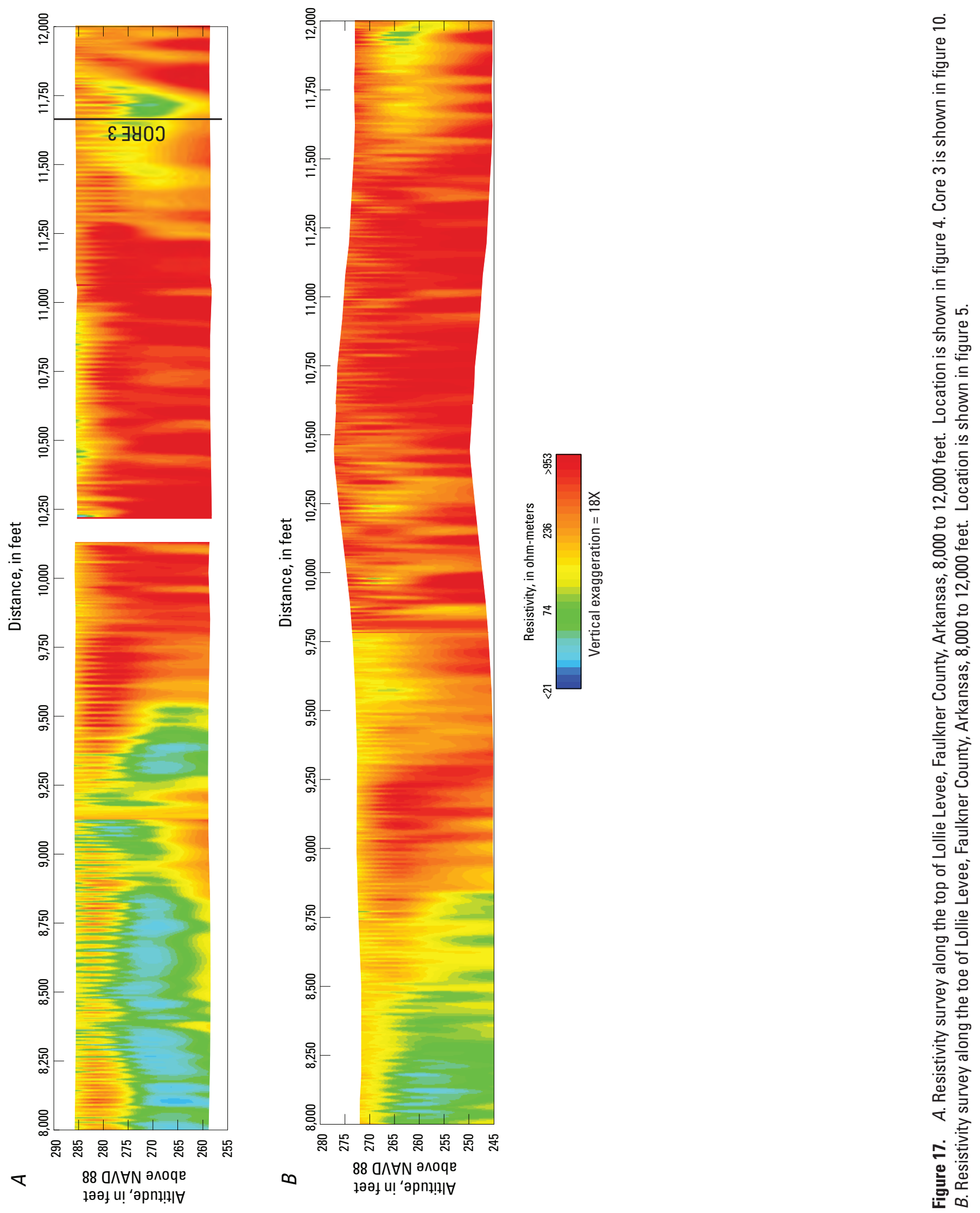

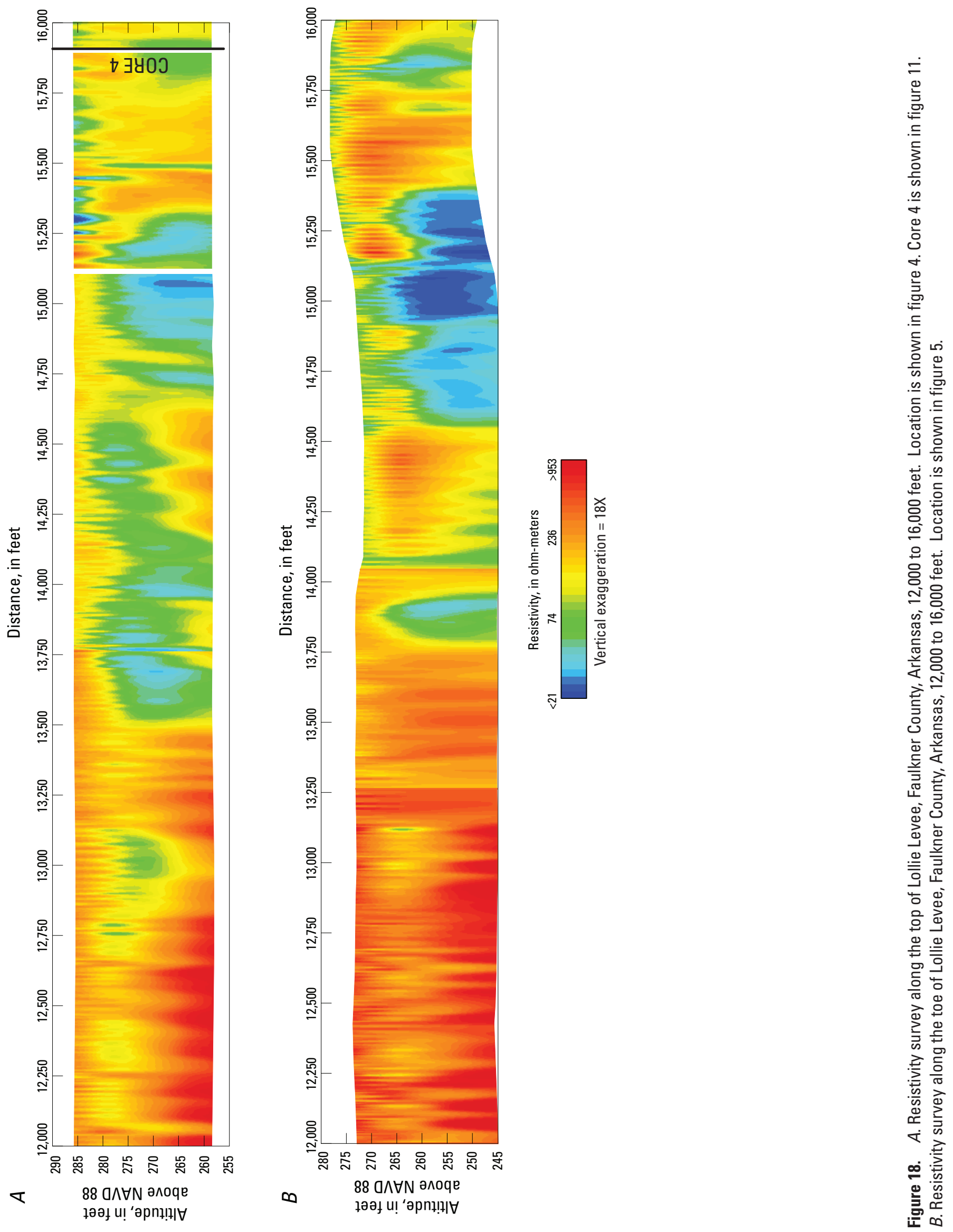

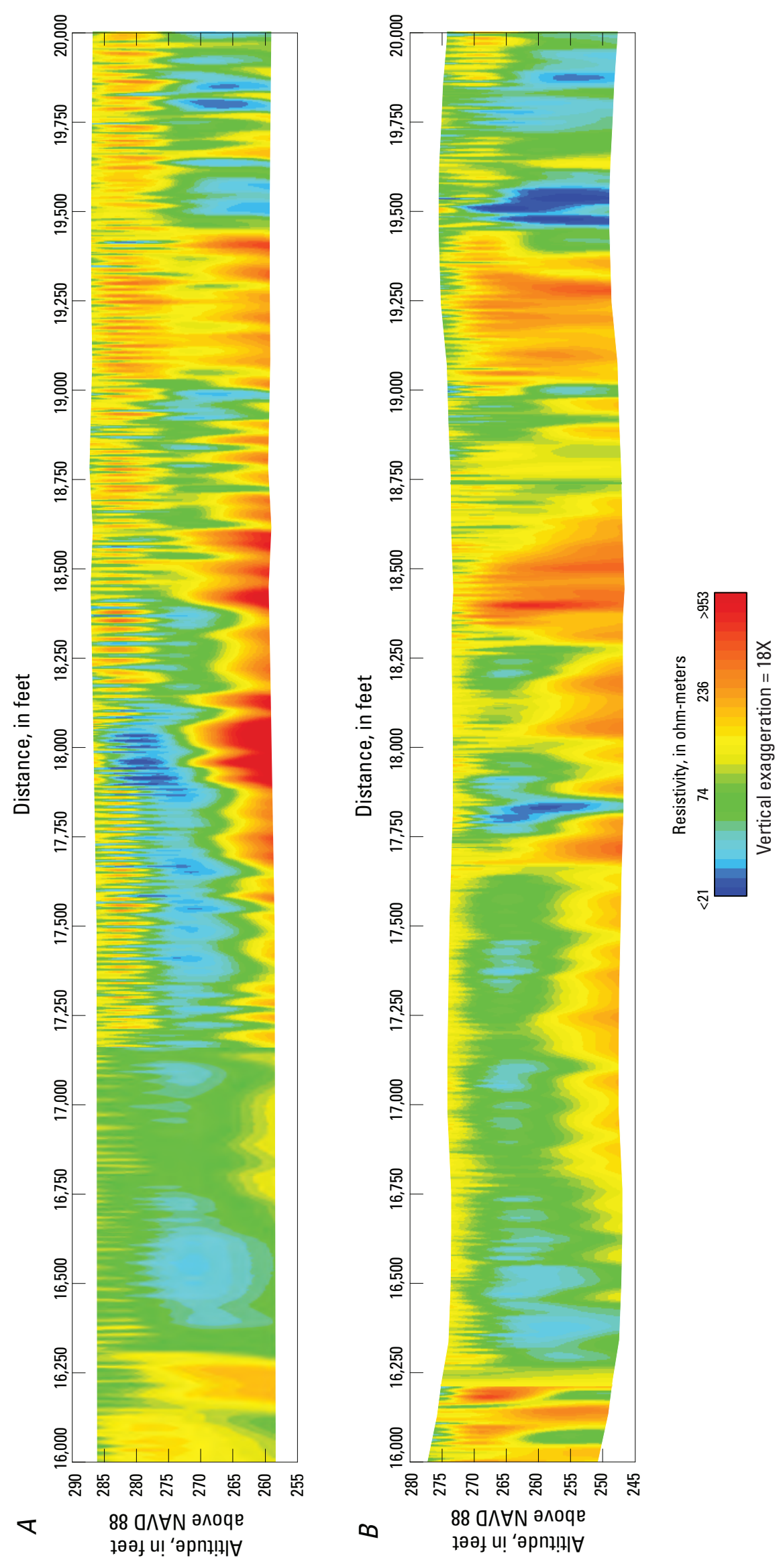

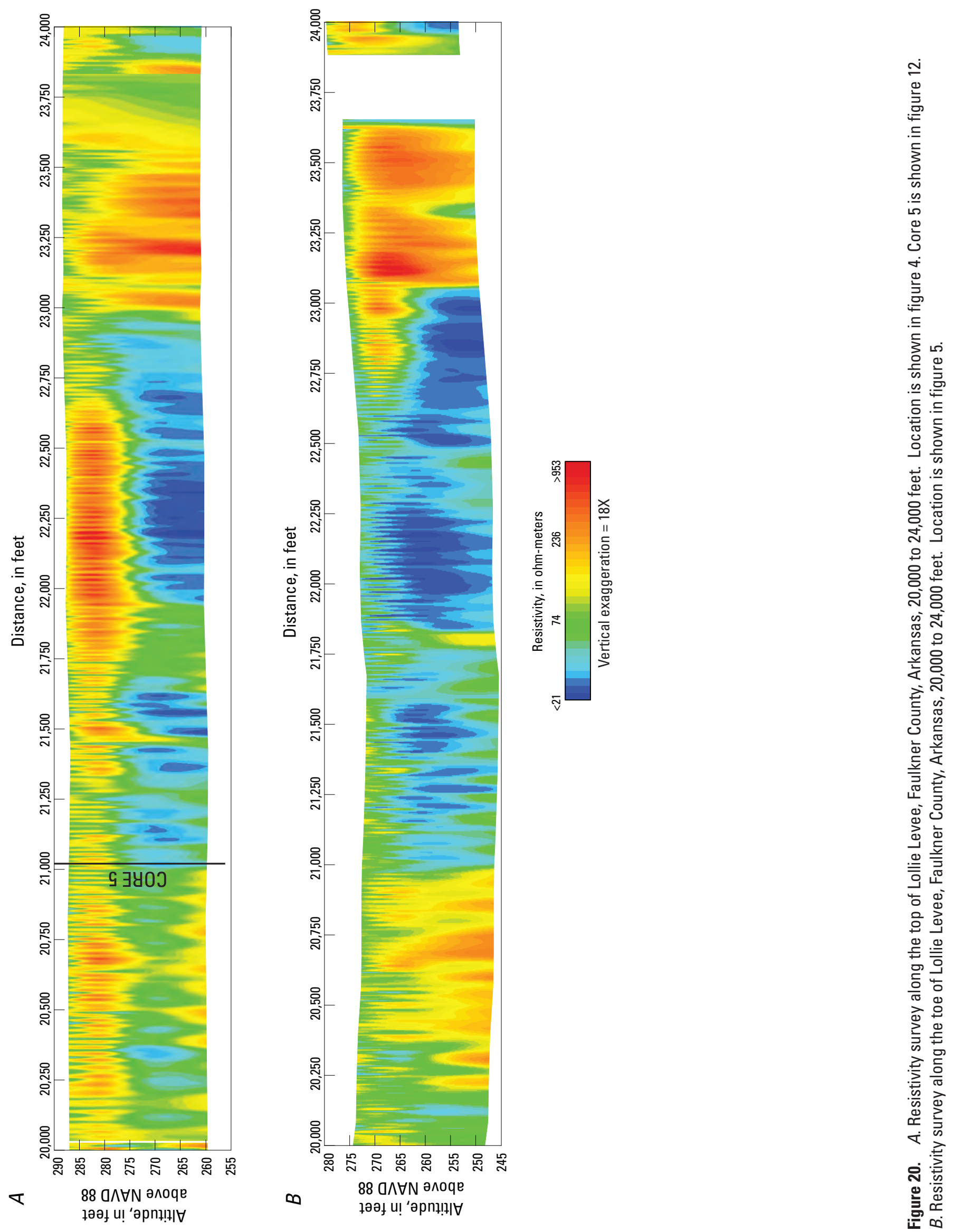

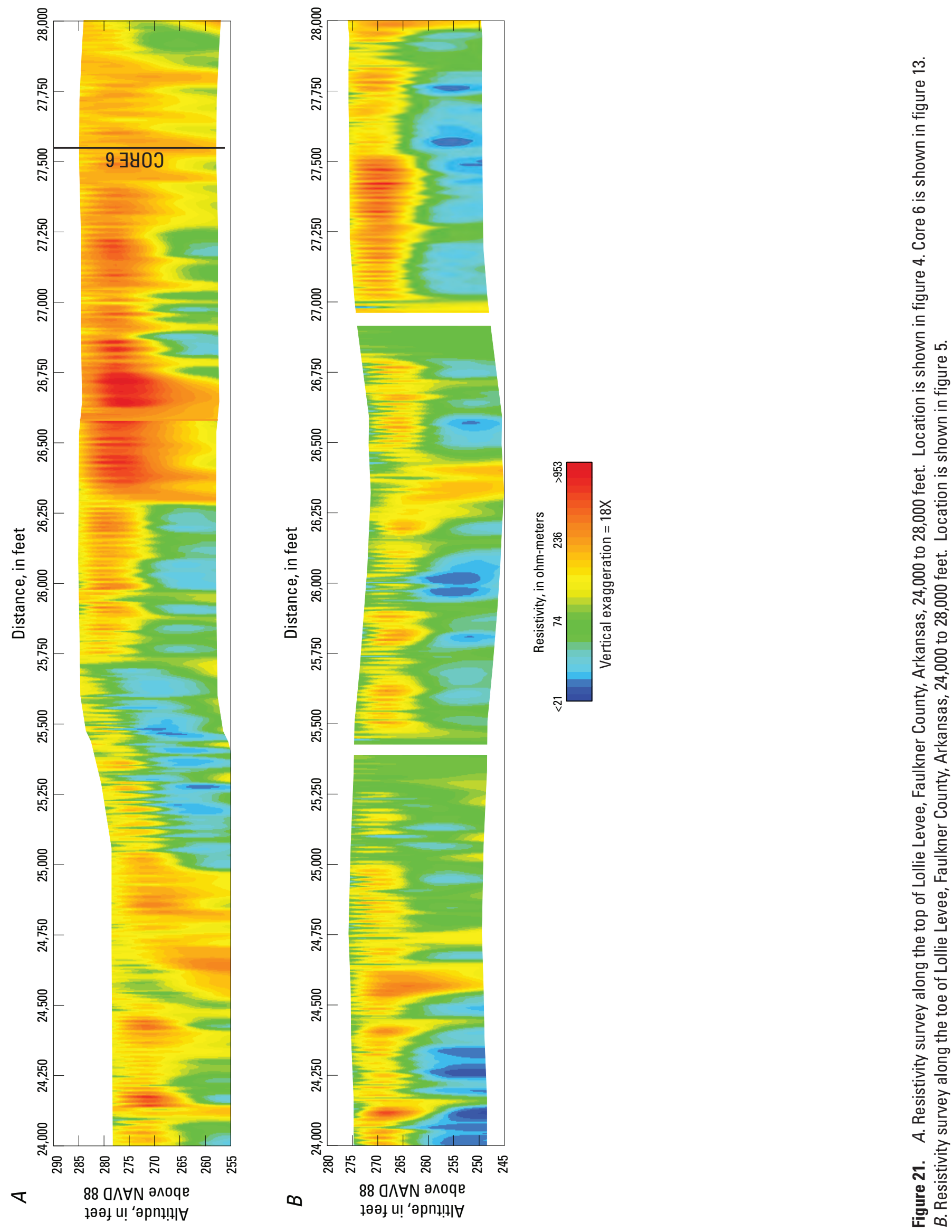

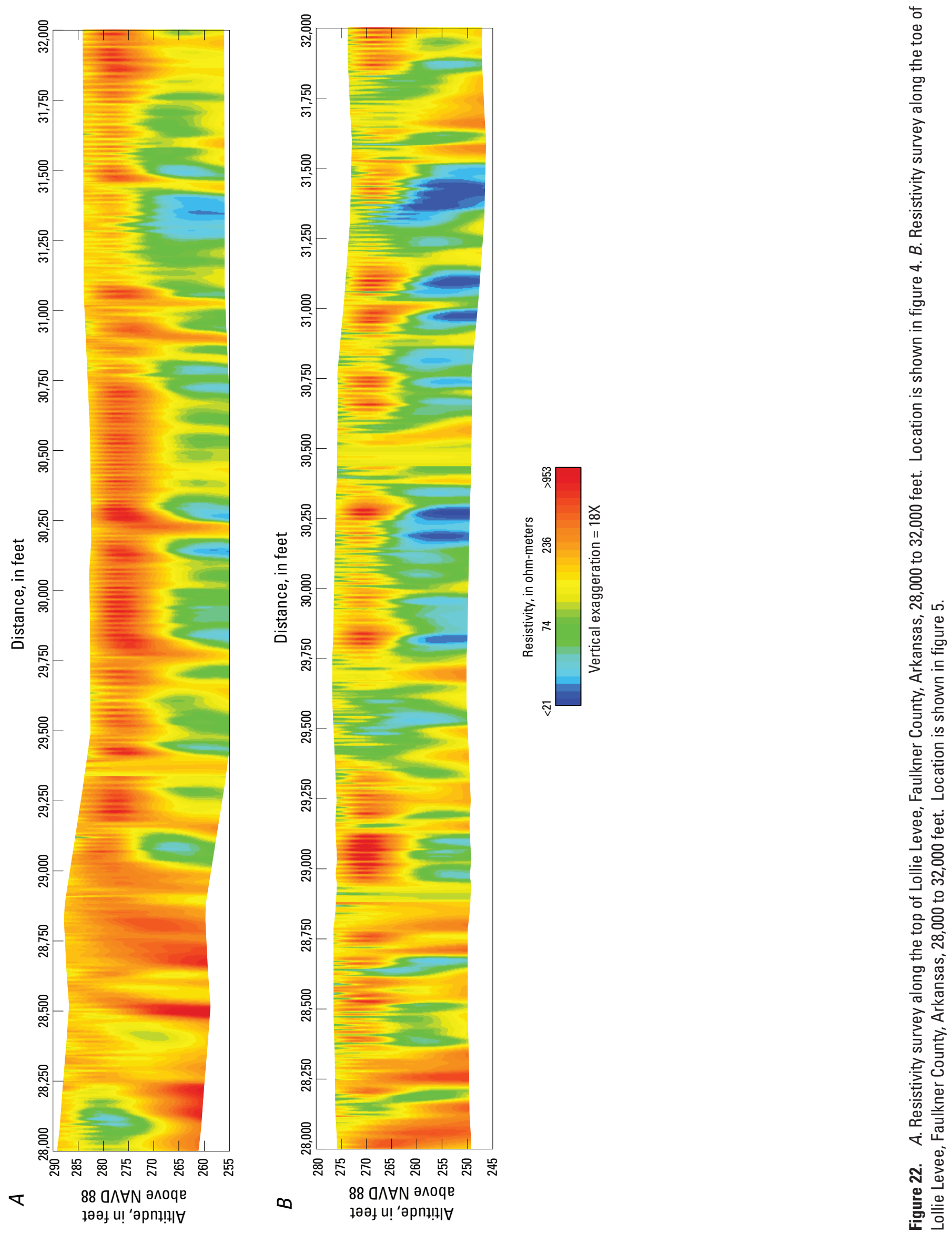

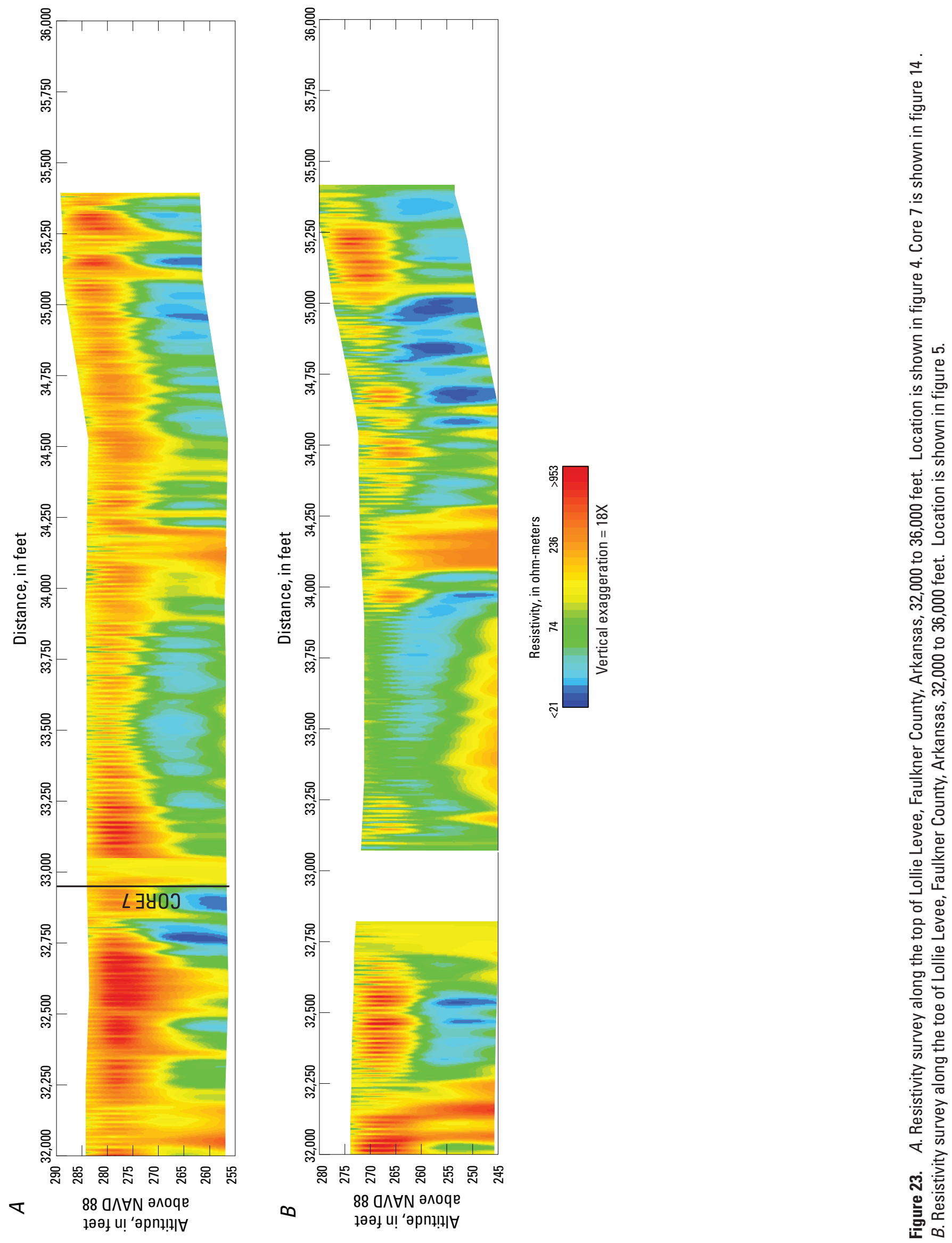


\section{Summary}

A geophysical characterization of Lollie Levee near Conway, Arkansas, was conducted in February 2011. A capacitively coupled resistivity survey (using Geometric's OhmMapper) was completed along the top and toe of the 6.7-mile levee. Field measurements of electrical resistivity were inverted to provide apparent resistivity models, which closely approximate "true" subsurface resistivity. As a qualitycontrol measure, cores and direct push logs were taken at approximately 1-mile intervals along the levee.

The capacitively coupled resistivity survey, the coring, and the direct push logs were used to characterize the geologic materials of the levee. Comparison of the cores and the direct push log data, along with published resistivity values (table 1 ), indicates that resistivity values of $200 \mathrm{Ohm}$-meters or greater represent relatively clean sand, with decreasing resistivity values occurring with increasing silt and clay content. The cores indicated that the levee is composed of a heterogeneous mixture of sand, silt, and clay. The capacitively coupled resistivity sections show that the composition of the levee varies spatially. Only a few areas of the levee are mostly low resistivity materials. From about 4,000 to 5,900 feet, the levee and underlying geologic materials are mostly low resistivity. From about 16,300 to 17,200 feet, the levee and the underlying geologic materials are composed mostly of low resistivity materials. Areas where the levee is composed mostly of high resistivity materials include from 0 to about 600 feet, from about 2,000 to 3,000 feet, from about 9,375 feet to 13,500 feet, from about 23,000 to 23,875 feet, and from about 26,300 to 29,000 feet. The remainder of the levee is composed of a mixture of high and low resistivity materials. The geologic materials underlying the levee vary spatially as a result of the geologic processes that deposited them. In general, the naturally deposited geologic materials underlying the levee are less resistive in the southern extent of the levee.

\section{References}

Advanced Geosciences, Inc., 2007, AGI Earthimager 2D inversion and modeling software: AGI Advamced Geosciences, Inc., accessed August 4, 2010, at http://www.agiusa.com/agi2dimg.shtml.
Asch, T.H., Deszcz-Pan, M., Burton, B.L., and Ball, L.B., 2008, Geophysical characterization of the American River levees, Sacramento, California, using electromagnetics, capacitively coupled resistivity, and DC resistivity: U.S. Geological Survey Open File Report 2008-1109, 23 p.

Butler, D.K, ed., 2005, Near-surface geophysics; Investigations in geophysics No. 13: Tulsa, Okla., Society of Exploration Geophysicists, 732 p.

Ball, L.B., Kress, W.H., Steele, G.V., Cannia, J.C., and Ander-sen, M.J., 2006, Determination of canal leakage potential using continuous resistivity profiling techniques, Interstate and Tri-State Canals, western Nebraska and eastern Wyoming, 2004: U.S. Geological Survey Scientific Investigations Report 2006-5032, 53 p. [available online at http://pubs.usgs.gov/sir/2006/5032/].

Geometrics, 2004, OhmMapper Capacitively Coupled Resistivity Meter: Geometrics OhmMapper Manual TR1- 29005-01, Rev. F., 147 p.

Geoprobe Systems, 2011, EC: Geoprobe Systems, accessed June 27, 2011, at geoprobe.com/ec.

Loke, M.H., 2004, RES2DINV version 3.54-Rapid 2D resistivity and IP inversion using the least-squares method-Geoelectrical Imaging 2-D and 3-D: Penang, Malaysia, Geotomo Software, 130 p.

Reynolds, J.M., 1997, An introduction to applied and environmental geophysics: Chichester, England, Wiley, $796 \mathrm{p}$.

Schulmeister, M.K., Butler, J.J., Jr., Healey, J.M., Zheng, L., Wysocki, D.A., and McCall, G.W., 2003, Directpush electrical conductivity logging for high-resolution hydrostratigraphic characterization: Ground Water Monitoring \& Remediation, v. 23, no. 3, p. 52-62. (Also available at http://onlinelibrary.wiley.com/ doi/10.1111/gwmr.2003.23.issue-3/issuetoc.)

Sharma, P.V., 1997, Environmental and engineering geophysics: Cambridge, United Kingdom, Cambridge University Press, 475 p. 
Publishing support provided by the Lafayette Publishing Service Center 


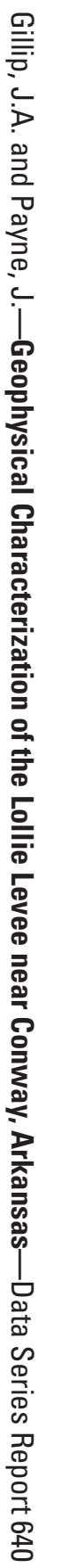

